\title{
An Update on Novel Therapeutic Warfronts of Extracellular Vesicles (EVs) in Cancer Treatment: Where We Are Standing Right Now and Where to Go in the Future
}

\author{
Muhammad Babar Khawar $\mathbb{D}^{1,2,3}$ Muddasir Hassan Abbasi ${ }^{1 D},{ }^{3,4}$ Zerwa Siddique, $^{5}$ \\ Amin Arif, ${ }^{3}$ and Nadeem Sheikh $\mathbb{1 0}^{3}$ \\ ${ }^{1}$ State Key Laboratory of Stem Cell and Reproductive Biology, Institute of Zoology, Chinese Academy of Sciences, \\ Beijing 100101, China \\ ${ }^{2}$ University of Chinese Academy of Sciences, Beijing 100049, China \\ ${ }^{3}$ Cell \& Molecular Biology Lab, Department of Zoology, University of the Punjab, Lahore, Pakistan \\ ${ }^{4}$ Department of Zoology, University of Okara, Okara, Pakistan \\ ${ }^{5}$ Centre for Applied Molecular Biology (CAMB), University of the Punjab, Lahore, Pakistan
}

Correspondence should be addressed to Muddasir Hassan Abbasi; muddygcs@gmail.com and Nadeem Sheikh; s_nadeem77@yahoo.com

Received 18 March 2019; Revised 3 June 2019; Accepted 4 July 2019; Published 25 July 2019

Academic Editor: Fabio Altieri

Copyright (C) 2019 Muhammad Babar Khawar et al. This is an open access article distributed under the Creative Commons Attribution License, which permits unrestricted use, distribution, and reproduction in any medium, provided the original work is properly cited.

\begin{abstract}
Extracellular vesicles (EVs) are a heterogeneous group of membrane-bounded vesicles that are believed to be produced and secreted by presumably all cell types under physiological and pathological conditions, including tumors. EVs are very important vehicles in intercellular communications for both shorter and longer distances and are able to deliver a wide range of cargos including proteins, lipids, and various species of nucleic acids effectively. EVs have been emerging as a novel biotherapeutic platform to efficiently deliver therapeutic cargos to treat a broad range of diseases including cancer. This vast potential of drug delivery lies in their abilities to carry a variety of cargos and their ease in crossing the biological membranes. Similarly, their presence in a variety of body fluids makes them a potential biomarker for early diagnosis, prognostication, and surveillance of cancer. Here, we discuss the relatively least and understudied aspects of EV biology and tried to highlight the obstacles and limitations in their clinical applications and also described most of the new warfronts to beat cancer at multiple stages. However, much more challenges still remain to evaluate EV-based therapeutics, and we are very much hopeful that the current work prompts further discovery.
\end{abstract}

\section{Introduction}

A bidirectional communication exists between cells and their immediate surroundings that ensures the survival of cells and is an essential factor for both normal and pathophysiological circumstances. Traditionally, such crosstalk was believed to occur via the release of soluble cellular factors (i.e., chemokines, cytokines, and growth factors) [1-3] or via direct cell-cell contact; however, involvement of the extracellular vesicle (EV) in cellular communication has changed the notion over the past decade $[4,5]$. Various eukaryotic cell types secrete these EVs in vitro, and their presence has been reported in a variety of body fluids including blood, bile, milk, and urine as well as in fecal matter [6]. A number of factors can induce the release of EVs, i.e., change in $\mathrm{pH}$, stress, damage, irradiation, lack of oxygen, exposure to complement proteins, and also as a result of cell activation (i.e., platelet activation) $[7,8]$. Secretion of EVs by plants and numerous pathogens including bacteria, Archaea, mycobacteria, and fungi is suggestive of an efficient evolutionarily conserved intercellular communication mechanism $[9,10]$.

Intercellular communication is an important phenomenon in multicellular organisms and usually mediated via direct contacts between the cells or via transfer of secretory 
molecules. Some of these secretory molecules are packaged into small lipid bilayer vesicles, known as extracellular vesicles (EVs), identified as a new means of intercellular communication. These EVs are major players in tumor progression and have shown a greater potential in therapeutic applications [11]. These diverse collections of vesicles are secreted by almost every type of cells [12]. Wolf identified these EVs for the first time in 1967 [13]. They successfully isolated minute particulate material from plasma free of platelets via ultracentrifugation. They originally named it as "platelet dust" [13] which was later on replaced by the currently known term "extracellular vesicles." Afterward in 1981, cultured normal and neoplastic cells were found to secrete membranous vesicles which were suspected to take part in physiological processes [14]. In the following few years, a similar kind of small vesicles, named "exosomes," was also found to be produced and secreted by reticulocytes in vitro [15]. Though only a little work was done in the early years following their discovery, recent rediscovery of EVs by cancer scientists has thrown the research into gear, and now, EV study is an exciting and rapidly growing field. The present term "EVs" was assigned by the International Society of Extracellular Vesicles (ISEV).

EVs play significant roles in multiple physiological processes including stem cell differentiation [16], autophagy [17], blood clotting [18], angiogenesis [19], immunity (innate and acquired) and immunomodulation [20,21], pregnancy [22], embryo implantation [23], reproduction, placental physiology, semen regulatory function [24], and tissue regeneration [19]. Furthermore, the role of EVs in neuronal regeneration and in the development and functioning of the nervous system has also been anticipated as novel arbitrators of communication between the cells $[25,26]$. Besides their contribution in normal physiology, EVs are also the key components in various pathologies like cancer [27-29] and development of multiple neurodegenerative diseases [30]. EVs mediate a variety of processes involved in cancer progression including inflammation, lymphogenesis, cell proliferation, epithelial-to-mesenchymal transition, angiogenesis, migration, suppression of the immune system, and metastasis-all of which are the so called "hallmarks of cancer" [31]. These extraordinary organelles have been associated with a number of aspects of cancer development and progression $[32,33]$, hence have a great potential to be used as biomarkers and ideal targets for novel future therapies for cancer treatment.

\section{EV Diversity and Classification}

EVs are currently classified as exosomes, microvesicles, microparticles, ectosomes, oncosomes, and apoptotic bodies [34] on the basis of their size, origin, and characteristics [35] (Figures 1 and 2). However, this classification is considered insufficient to cover the heterogeneity that lies in cargo and their uncountable roles [36]. Exosomes are the best characterized and are less variable in size (ranging 40-150 nm) than other subtypes. Exosomes are produced as a result of membrane invaginations of endosomes resulting in the formation of multivesicular bodies (MVBs) and are stored as intraluminal vesicles (ILVs) that are secreted out of the cell once MVB fused with the plasma membrane at a certain point [37-39] (Figure 1).

Microvesicles (MVs), sometimes also referred to as ectosomes or microparticles or membrane particles, are larger and more heterogeneous in size (ranging from $100 \mathrm{~nm}$ to several microns) than exosomes $[40,41]$. These cell surface-derived EVs are produced as a result of bulging of the plasma membrane and are ultimately shed from the cell surface as these blebs undergo fission upon proper stimulation [40, 41]. MVs are known to be full of phosphatidylserine and have several other lipid components [42]. MVs were firstly identified to be released from RBCs [43] and activated blood platelets [44] and were thought to contribute in the regulation of coagulation cascade [45]. Their formation is endorsed by increased $\mathrm{Ca}^{2+}$ levels that do so by altering the phospholipid distribution within the plasma membrane. A steady state or classical asymmetric lipid composition exists along the plasma membrane and is characterized by the existence of aminophospholipids towards the cytoplasmic side while phospholipids are on the side facing extracellular environment [46]. A variety of membrane enzymes including floppase, flippase, translocase, and scramblase help in the maintenance of this intricate balance. Increased intracellular $\mathrm{Ca}^{2+}$ in association with cytoskeleton modification [44] and recruitment of scramblase $\left(\mathrm{a} \mathrm{Ca}^{2+}\right.$-dependent enzyme) [47] relocate phosphatidylserine from the inner side to the outer side [48] in an ATP-dependent manner [49]. ADP-ribosylation factor 6- (ARF6-) mediated invasion and cytoskeletal remodeling in prostate and breast cancers are accused of the shedding MVs and all other classes of EVs [50] (Figure 1). Considering the heterogeneity in the size of MVs, the presence of numerous subpopulations can be speculated within this subdivision of EVs. The term "oncosomes" was coined to describe the MVs or EVs secreted by cancer cells [51]. It is noteworthy that the term "large oncosomes (LO)" is referred to as a specific class of EVs and used to describe a comparatively larger size $(1-10 \mu \mathrm{m})$ of subtype MVs, which originate directly from the plasma membrane, produced by cancer cells $[52,53]$.

Apoptotic bodies, range in size from 800 to $5000 \mathrm{~nm}$, are produced during cellular blebbing and released by cells undergoing programmed cell death [41]. However, how they affect other cells is not well-studied yet.

EVs are usually classified on the basis of their origin; however, this classification and the current techniques employed for the identification of these EVs are insufficient to distinguish clearly each type of EV separately [54]. Some vesicles also originated from the nanotubular projections present on plasma membranes [55]. Recently, the presence of very small nanovesicles $(8-12 \mathrm{~nm})$ has been reported in peripheral blood [56] that was errantly separated along with exosomes. It would not be wrong to say that the current nomenclature has not been without debate, and size attributes of EV subtypes are ambiguous to fully distinguish them separately $[6,57]$. As a matter of fact, the isolation techniques and protocols are still in the development process, and consensus best practices have not yet been achieved resulting in differences in EV subpopulations being evaluated between 


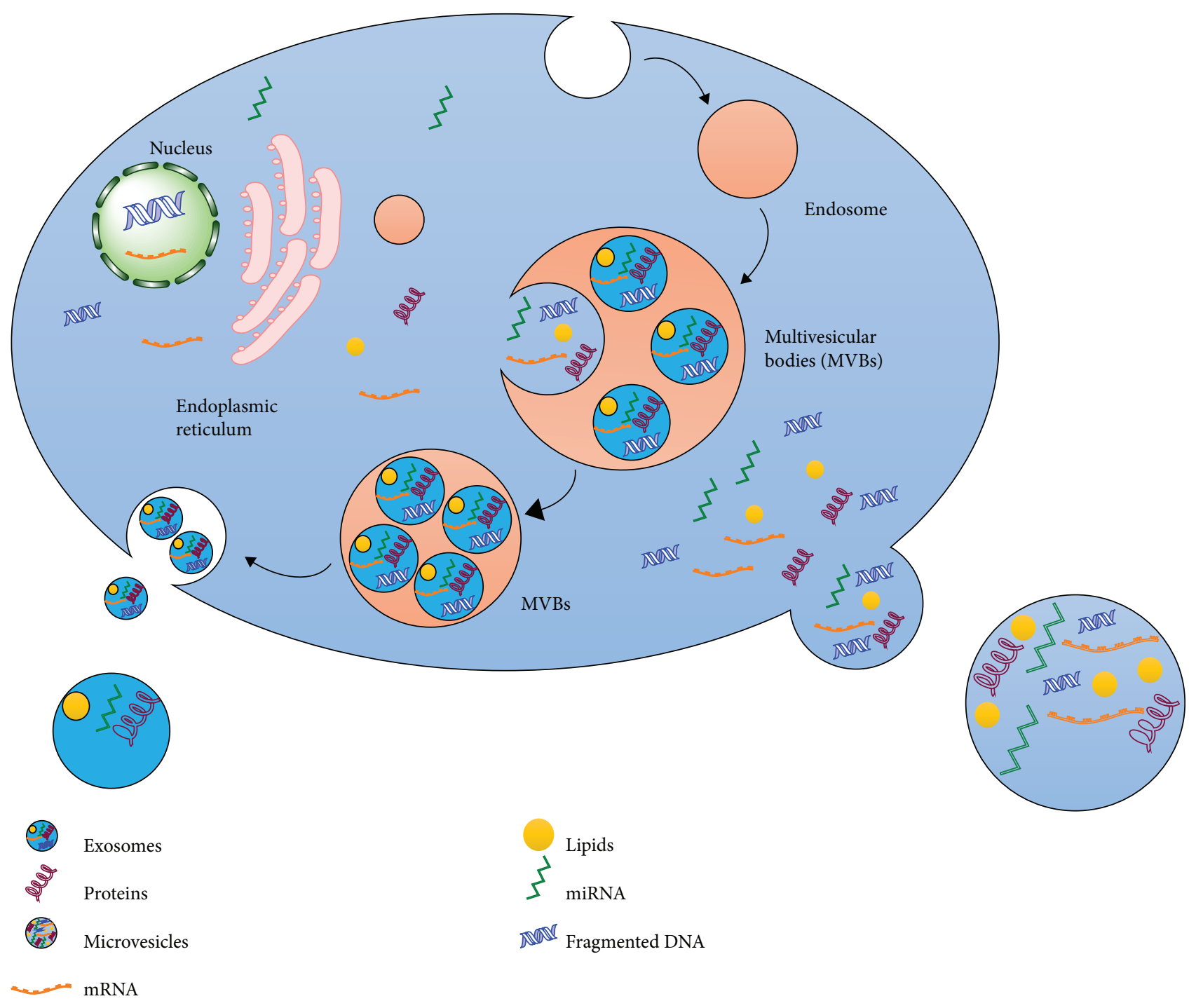

FIGURE 1: Biogenesis of exosomes and microvesicles: a schematic representation of endosome formation by internalizing the extracellular substances by invagination and pinching of the plasma membrane via endocytosis. These endosomes are transformed to multivesicular bodies (MVBs) by taking up a variety of cytosolic contents (proteins, nucleic acids, and various metabolites) via inward budding of late endosomes. Later, these MVBs may fuse with the plasma membrane at certain points to release the internal vesicles named as "exosomes." In contrast, microvesicles are formed due to outward protrusion/blebbing of the plasma membrane. A diverse array of cargos is packed into these protrusions which pinched off the parent cell giving rise to microvesicles.

investigations [36,58]. Therefore, the mode of biogenesis and cargo within EVs may prove crucial in establishing a more proper criterion for their classification. In line with this speculation, EV subpopulations have been characterized recently on the basis of their size, density, cargo, and their effects on target cells $[36,59,60]$. Therefore, new EV classes and modifications in the current classification criteria are expected to emerge as the field progresses. Additional vesicle types used to study lipid and protein behavior have also been reported, however not classified along with the above given vesicles. For instance, a number of stimuli, i.e., some chemicals (paraformaldehyde and dithiothreitol), salts, and laser treatment may result in the formation of giant plasma membrane vesicles (GPMVs) in live cells [61-63]. These vesicles are large sized and help in understanding the lipid and protein organization existing along the plasma membrane $[62,64,65]$. There are many other additional vesicle types including small, large, and giant uni- and multilamellar lipid vesicles [66] along with artificial plasma membrane vesicles [67] that are exclusively synthesized in vitro. These extraordinary vesicle species are employed therapeutically to enhance the stability and uptake of drugs and other biological molecules probably via the same mechanism adapted by natural EVs $[68,69]$. Currently, most, if not all, cell types are believed to produce EVs [70, 71]; however, diseased states and stress not only upregulate their production but also alter the cargo contained within [72].

Considering the unexpected pace in the growth of EVrelated information, Minimal Information for Studies of Extracellular Vesicles ("MISEV") guidelines were proposed 

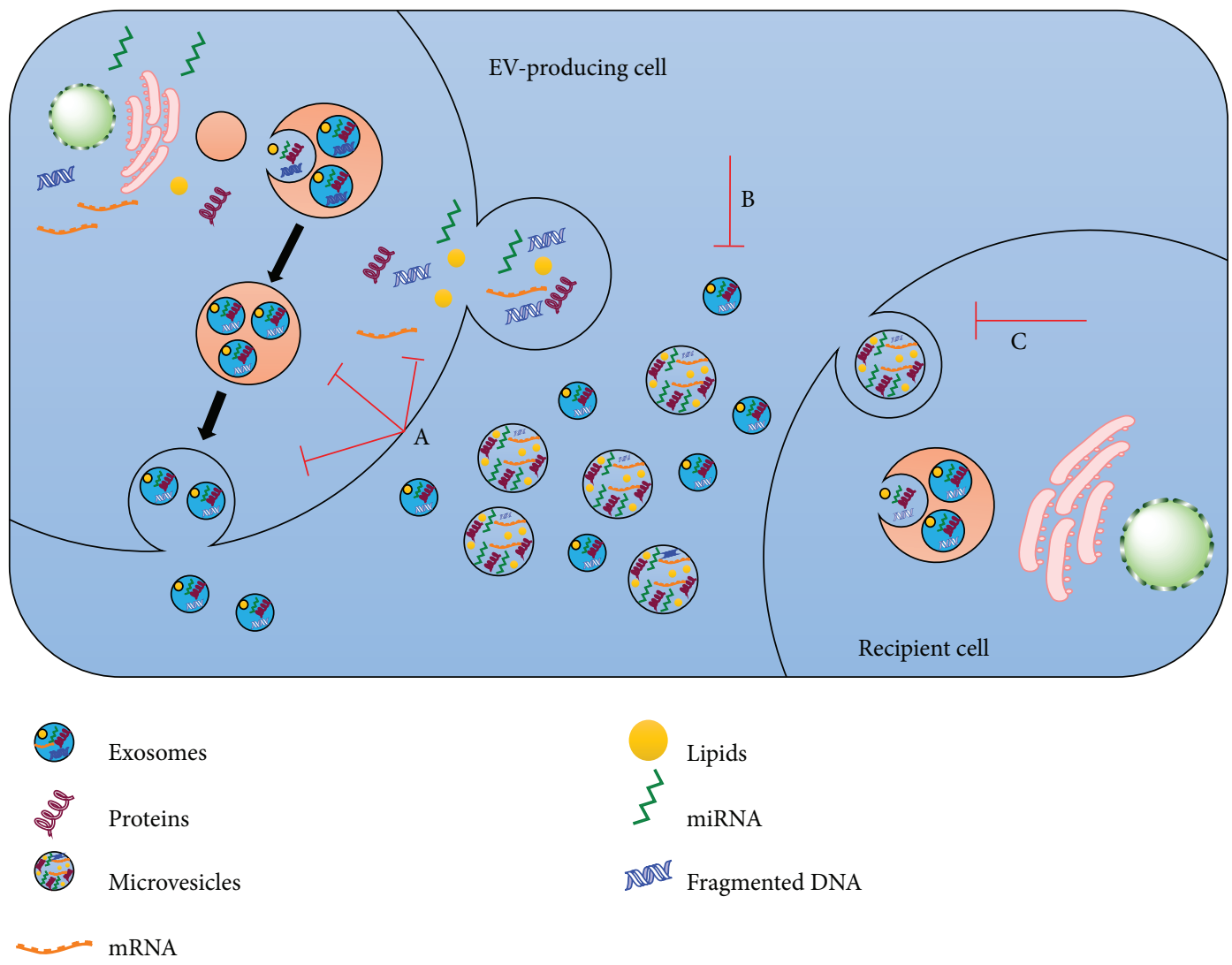

FIgure 2: Therapeutic strategies to target EVs for cancer treatment. There are a number of potential ways to target the EV-mediated intercellular communication. (A) EV biogenesis or release can be targeted via interfering the specific components involved in EV production or surface shedding. (B) EVs can be targeted and specifically removed from the circulation using different substances, i.e., specific antibodies. (C) EV uptake/internalization by the recipient cells can be interrupted by targeting the EV ligands or cell surface receptors.

by ISEV five years ago and have been updated last year on the basis of evolution of the collective knowledge of the field in these past four years. These guidelines equipped the EV biologist with a collection of standardized protocols and procedures for a better documenting of EVassociated functions [34].

\section{Therapeutic Approaches to Target EVs}

As described before, EVs are major players in tumor progression via the transfer of cargo within them. As a matter of fact, the pathways targeted by EVs differ largely from conventional methods, i.e., chemotherapy or molecular targeting drugs. Therefore, three potential therapeutic approaches are proposed in this regard: (i) inhibition of EV formation, (ii) eradication of circulating EVs, and (iii) ablation of EV absorption [73] (Figure 2). A large number of investigations both in vivo and in vitro have stressed the efficacy of inhibiting EV production in cancer reduction. For instance, blockade of EV secretion and miR-210-3p transfer and subsequently suppression of angiogenesis and metastasis were observed, in a xenograft mouse model, as a result of nSMase2-knockdown [74]. In another study, repression of ovarian cancer dissemination, as a result of inhibition of EV production, was observed upon nSMase2-knockdown [75]. In addition to it, to date, a large number of other mole- cules involved in EV production, i.e., RAB27A, RAB27B, and TSG101, have been exploited to reduce the production of cancer-derived EVs [76, 77]. Although suppression of EV production seems quite an efficient strategy in cancer treatment, targeting genes involved in this pathway will affect many of the important biological activities of normal cells as they are the mode of intercellular communication [73]. For instance, nSMase2 has been found to express in normal neural cells [78]. Furthermore, downregulation of these genes showed different extent of their inhibitory effects on EV production among different cancer types. For example, there was no effect on EV production upon ablation of nSMase2 in the prostate cancer cell line [79]. Therefore, it is the need of the current time and would be a future challenge to identify genes associated with cancer type-specific EV production.

A novel therapeutic strategy to remove the circulating EVs was devised by Marleau and coworkers in 2012. A hemofiltration system was developed that was able to specifically trap the circulating cancer cell-derived HER2-expressing EVs [80]. These HER2-positive EVs hinder the available therapies and subsequently promote cancer development [81]; therefore, selectively targeting the HER-2-expressing EVs may prove a better approach in breast cancer treatment. In line with it, the circulating EVs have also been found to establish a premetastatic niche and subsequently promote cancer metastasis [33]. Hence, it can be speculated easily that 
elimination of these circulating EVs may help in the prevention of cancer metastasis. Recently, a new idea has been adapted to target circulating EVs in a human breast cancer xenograft mouse model [82]. In this study, a pronounced decrease in metastatic activity was observed upon the administration of anti-CD9 and CD63 (two of the most enriched receptors on the EV surface) antibodies [82]. However, there were found no prominent effects on primary site growth. Moreover, macrophages were utilized to internalize the EVs tagged by anti-CD9 and CD63 and were not allowed to promote cancer progression. Furthermore, more in-depth studies are required as anti-CD9 and CD63 antibodies are unable to selectively target the cancer-derived EVs in humans. However, identification of cancer-specific molecules on the EV surface and development of specific antibodies against them can likely help in eliminating the circulating EVs and subsequently prove effective in cancer treatment. Therefore, that investigation was believed to devise a novel treatment strategy for cancer.

Microvesicle cargo is simply internalized directly into the cytoplasm via plasma membrane-EV fusion while intact vesicles are taken up via several ways for transferring to the lysosomal or endosomal pathway [83-85]. The multiple ways of EV internalization include micropinocytosis [86, 87], clathrin and caveolin-mediated endocytosis, phagocytosis, and lipid raft endocytosis $[88,89]$. In addition to it, another key factor that favors the fusion of EV membranes with the recipient cells is the low $\mathrm{pH}$ conditions produced by the tumor microenvironment [88]. Therefore, disruption of EV internalization may help in the formulation of new and better therapeutic approaches to prevent tumor progression and in cancer treatment. Recently, heparan sulfate proteoglycans (HSPGs) were found to act as a receptor of GBM-derived EVs [89]. A dose-dependent inhibition of EV uptake and a clear suppression of EV-dependent cell migration were seen in GBM in the presence of an HS mimetic, heparin. A number of molecules capable of EV internalization have been described to date, and many more are expected to be reported in the near future $[84,90,91]$. Despite the identification of several molecules responsible for EV internalization, the mechanism involved in this internalization is not very clear. However, caveolin-dependent endocytosis has been reported as a primary route for internalization of multiple myeloma cell-derived exosomes while some of the exosomes were taken up via macropinocytosis and membrane fusion [92]. Glycans are involved in energy storage and also serve as structural components that have been recently described to play an important role in several molecular recognition events. Glycans not only modulate recognition at the cell level but also regulate the intracellular traffic and folding of individual proteins $[93,94]$. Abnormal glycosylation usually interrupts these crucial recognition events and may lead to cancer or other disorders like lysosomal storage diseases [94]. Although we are not familiar with the function of glycoconjugates in EV biology at present, several novel strategies that utilize EV glycosylation have already been emerging. Indeed, an extraordinary interest has been emerging recently in studying the effects of glycosylation modulation of EVs and their cargo. Glycoengineering is a promising field that is highly exploited to optimize the stability and alter the pharmacokinetics of protein-based drugs $[95,96]$. This concept was proved for EVs by engineering Lamp2b protein (exosomal membrane protein) [97]. Furthermore, N-glycosylation was found to protect the peptides from lysosomal proteolysis [97]. In fact, a twofold increase in the efficiency of exosome delivery was found in the nervous system upon glycosylation of the desired peptides. Therefore, this strategy can be speculated the best choice to improve the uptake efficiency of peptide-targeted vesicles. Neuroblastoma-derived exosomes were found highly enriched in glycosphingolipids, and these glycans showed a huge therapeutic potential against Alzheimer's disease as they were capable of scavenging the $\beta$-amyloid [98]. The formation of hybrid exosomes having unique lipid components with the liposomes [99] has shown an enormous therapeutic potential of the glycolipid cargoes. These few experiments are the EV glycoengineering efforts that advocate a promising platform and future directions. Briefly, glycosylation can be exploited in manipulating the cargo protein recruitment and offers novel therapeutic targeting approaches [100, 101]. One more aspect that can be utilized to modulate the physicochemical characteristics of EVs is the sialylation status as it is capable of altering the vesicle charge [102]. This approach is yet to be achieved, but the availability of massive information on glycoengineering can be applied to EVs [103].

Unluckily, currently, there are no data available about the effects of inhibition of $\mathrm{EV}$ internalization under in vivo conditions. One of the prime reasons behind this insufficiency of investigations is that the cancer cell-associated EV uptake pathway is not quite clear yet. To ensure the integrity of normal cell homeostasis, it is necessary to fully understand the cancer-specific EV uptake pathways by the cancer biologists for therapeutic development. The presence of different EV protein markers has been recently described in different fractions of EVs; furthermore, these fractions were found to have different molecular and biological characteristics [36]. Likewise, immature dendritic cells have been found to release two EV subpopulations (small and large EVs) that were further found to affect the $\mathrm{T}$ helper cell in a different manner [104]. Therefore, identifying the EV subpopulations, their effects on target cells, and specific internalization pathway would be the best approach for better future therapies. On the basis of the above given contexts, inhibition of EV transfer could be speculated to be employed as a novel therapeutic approach in suppressing the tumor progression. Despite a great number of challenges, outstanding advances and pace in understanding of EVs are promising a better future [11].

\section{EVs as Potent Novel Drug Delivery Systems}

EVs have been emerging as attractive novel entities for drug delivery because of their structural analogy with liposomes [105]. Liposomes have proven their efficiency as a novel drug carrier and have been widely employed for drug delivery as they are very similar in composition with the plasma membranes [106]. Since that time, multiple commercialized liposome-based products like Myocet (an approved nonpegylated liposomal doxorubicin highly practiced against 
metastatic breast cancer), DaunoXome (an approved liposome employed against advanced HIV-associated Kaposi's sarcoma to deliver daunorubicin (DNR)), and Depocyt (approved against lymphomatous meningitis) have been introduced for therapeutic purposes [107]. Liposomal research has laid down the foundation to explore their physicochemical properties and stability for their employment as novel drug delivery agents [108-110]. Exploiting EVs is a better choice and more advantageous than liposomes as they are naturally produced by the cells and can easily transfer the desired drugs. These properties make EVs the best choice to be utilized as drug delivery agents even across the bloodbrain barrier (BBB) [111]. Some of the potential EVs that have been used recently as drug delivery vehicles in different types of cancer are summarized in Table 1.

\section{EVs in Cancer Treatment}

A huge number of studies have provided the evidences of the use of these EVs as a splendid tool to deliver small interfering RNAs and other synthetic molecules for therapeutic purposes [123]. EVs have been employed in a number of animal model studies developed for different diseases as potent therapeutic DDSs [124]. Moreover, they are splendid antitumor DDSs as EVs are capable of passively targeting tumors because of their enhanced permeation and retention [125]. It is of great interest that genetically engineered EVs as targeted DDSs offer a dynamic and handy platform for specific and target-oriented drug delivery with better therapeutic outcomes. Recently, an efficient DDS was developed for the successful transfer of siRNA to the CNS via modified dendritic cell- (DC-) derived EVs [111]. The DCs, isolated from mice, were transected with a plasmid expressing EV surface protein, lysosome-associated membrane glycoprotein $2 \mathrm{~b}$ (Lamp2b), along with rabies viral glycoprotein (RVG) that helps in binding with acetylcholine receptor. An efficient brain-targeting gene knockdown was observed by GAPDH siRNA-loaded DC-derived EVs, signifying their prospect as effective targeted DDSs. Effective delivery of both genes and proteins represents the potential of these extraordinary EVs to be served as cell-derived liposome-like nanoplatforms to cure various diseases including cancer [5, 40, 41, 126, 127]. Moreover, a zip code-like 25-nt sequence has been found to enhance the packaging of miRNAs into EVs and has pushed the research one step forward by guaranteeing high-yielding EVs loaded with various RNAs [128]. Amazingly, siRNA have also been utilized as therapeutics against tumors via bacterial outer membrane vesicles (OMVs). This study has highlighted the significance of bacteria in the production of biological nanovesicles and their application in drug delivery [129]. Furthermore, they are also being employed to transfer chemotherapeutic agents in addition to biomolecule-based drugs to enhance their efficiency and to minimize the possible side effects associated with them. For instance, an effective inhibition and successful reduction of breast and colon cancers have been achieved by encapsulation of the EVs with doxorubicin and curcumin $[130,131]$. The outcomes of these investigations suggest that EVs offer an effective way to suppress cancerous tumors by delivering a wide range of the chemotherapeutics drugs. Recently, doxorubicin (chemotherapeutic drug) have been successfully delivered, via an i.v. injection, to $\alpha \mathrm{v}$ integrin-positive breast cancer cells via exosomes isolated from Lamp2b-iRGD peptide expressing engineered immature mouse DCs (imDCs), and a remarkable suppression in tumor growth was observed [130]. Moreover, these therapeutic exosomes were less toxic and very effectual in cancer inhibition. Furthermore, their effectiveness in delivering the therapeutic cargo has also been authenticated employing multiple tumor models [132] including hepatocarcinoma [133], lymphocytic leukemia [134], and pancreas [135] and prostate [136] cancers.

Some of the potent EVs that have been utilized recently in different types of cancer are summarized in Table 2.

\section{EV-Associated Antitumor ncRNAs}

A number of attributes, including their release from the parent cells, delivery via the circulatory system, targeted cell uptake, and selective cargo transport, make them a promising and sizzling object for the selective drug delivery carrier [73, 144]. Therefore, investigators are proposing innovative and dynamic approaches for the modification of EVs specifically exosomes to cope with the current clinical challenges and therapeutic needs [145-147]. One of such approaches involves the direct modification of the contents of isolated exosomes. For instance, siRNAs and shRNAs have been incorporated into fibroblast-like mesenchymal stem cell-derived exosomes via electroporation to target KRAS $^{\mathrm{G12D}}$ mutation of pancreatic cancer [143]. Therapeutic use of natural exosomes is highly advantageous for several reasons compared to synthetic liposomes. For instance, exosomes are prevented from being phagocytosed by monocytes and macrophages due to the presence of CD47 on the exosomal membrane. Furthermore, the accumulation and uptake of exosomes by cancerous tissues are facilitated by some yet unknown native proteins present on the exosomal surface. Consequently, these "chimeric" exosomes were found to effectively execute an enhanced survival and reduced metastasis [143]. Another approach is to stimulate the parental cells to release modified exosomes. For example, exosomes containing miR-143 were obtained from MSCs pretreated with medium containing synthetic miR-143 and were found to successfully deliver these miRNAs to osteosarcoma cells to hamper their metastatic activity in vitro [148].

\section{Application of EVs as Cancer Vaccines}

Considering their production by every cell and their immune-modulatory effects, they can be employed for diagnostic purposes. Similarly, exosomes have shown antigenpresenting and immune-stimulatory potential and are being utilized for triggering antitumor responses. Moreover, release of exosomes from tumor cells is suggestive of their involvement in tumor microenvironments [149]. Cancer- and immune cell-derived EVs are capable of inducing immunostimulation to recipient cells. This prospect can presume the use of EVs as cancer vaccines, either derived from APCs or 


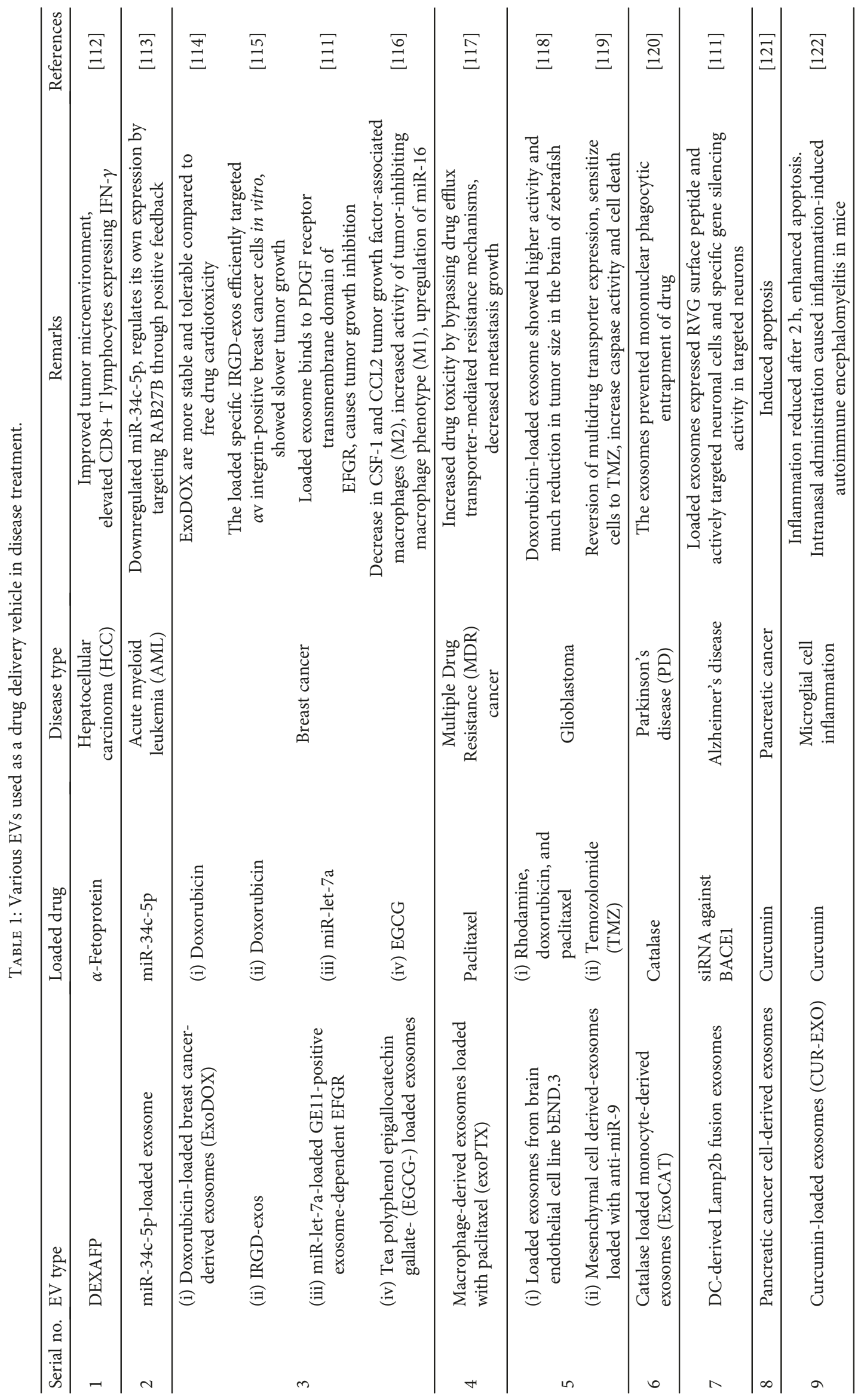




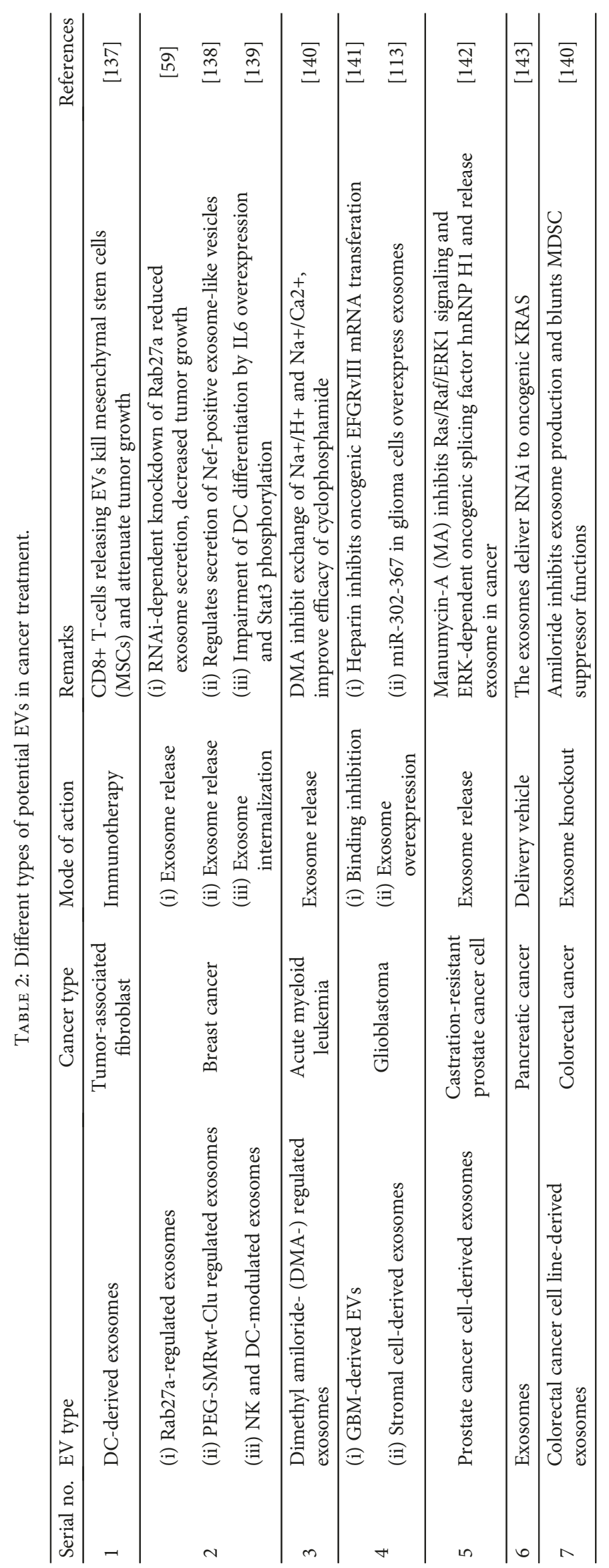


derived by tumors themselves [150]. These cancer-derived EVs are believed as potential proimmune elements because of the presence of several stimulatory molecules, i.e., heat shock proteins $[151,152]$ and numerous tumor antigens on their surface $[151,153,154]$. There is an ample amount of data available in favor of EVs as potent immunesuppressive agents $[150,155,156]$. Therefore, an encounter between the immune system and tumor EVs takes place in an immune-stimulatory vs. an immune-suppressive context [150], and by considering their immune-stimulatory features, these tumor EVs have been employed clinically as cancer vaccines [157]. In addition to a previous report of Kunigelis and Graner [150], another trial is also available on "clinicaltrials.gov" (NCT01550523). This trial was performed on patients who had resected the tumors and failed the prior therapies; an antisense construct against IGF1R was used to induce apoptotic cell death in autologous tumor cells. The cells were positioned in a biodiffusion chamber, and soluble ingredients, for the induction of immune response, were allowed to be released. Next, the chamber was inserted in the rectus sheath and was detached after 24 hours. Some of the subjects were found to develop deep vein thrombosis and were subjected to enoxaparin treatment to get rid of this problem. Except this minor trouble, the therapy was believed to be safe as some subjects were found to show complete response and some were found to show partial response under two (2) to twenty-seven- (27-) week timespan [158]. In the second phase I trial, the glioma cellderived exosomes were referred to as immune stimulators by the authors [159]. The tumor-challenged mice were safeguarded via implanting chamber-based vaccine in this case probably due to the formation and release of antigenbearing immunostimulatory exosomes. In line with these investigations, DC-derived EVs/exosomes (also referred to as dexosomes/DEX) have also been subjected to phase II trials [150]. For this purpose, multiple types of antigens (peptides, proteins, and tumor lysate) are loaded to DCs isolated from patients. Subsequently, the exosomes produced by the cells in the culture supernatants are utilized as cell-free cancer vaccines. Recently, inoperable non-small-cell lung cancer patients were subjected to chemotherapy followed by DEXbased immunotherapy for maintenance. For this purpose, MAGE/NY ESO/MART1 peptides were introduced in DCs via the pulse and cultured with gamma interferon (IFNG). Subsequently, DEX were isolated, and 1-27 injections of DEX were given to the patients. A median overall survival of fifteen (15) months along with median progression-free survival (PFS) of 2.2 months was found in the treated patients. An increased number of NK cells and an enhanced activity associated with NKp30 (NK surface ligand) were found in subjects with $>2.2$ month PFS [160]. It is of great interest that NK cell activation was found in an earlier trial [161]; in addition, an improvement of $\mathrm{T}$ cell responses but no induction of tumor-specific T cells was found upon IFNG addition. Upon cessation of chemotherapy, about $50 \%$ of the patients with PFS did not reach primary endpoint at 4 months with this trial; however, large-scale DEX production could be adapted to treat very advanced cancer. The updates about the use of either tumor-derived or immune cell- derived EVs to promote antitumor responses and cancer suppression are continuing to grow. A huge number of investigations are available in favor of tumor EV-driven immune suppression [150, 156, 162-164]. Inflammation is a major contributor in immune-mediated progression and tumor suppression [165], and nucleotide receptors are common mediators of inflammatory reaction [166] and cancer [167]. One of such receptor families is the purinoreceptor family that participates in immune responses mediated by EVs in immunity, inflammation, and cancer settings [168].

Radiotherapy is a new choice in enhancing the immunotherapy effects; however, radiations led to the oxidation, degradation, and accumulation of the DNA in the cytosol. This accumulation of DNA encourages the release of interferon-b from tumor cells via activation of the cGAS/STING-mediated DNA-sensing pathway. STING is a key signaling component that responds to pathogen-derived DNA by inducing the production of a variety of cytokines and type-I IFNs upon activation by its ligand, cyclic GMP-AMP (cGAMP). Cyclic GMP-AMP synthase (cGAS) associates with the pathogenic DNA and led to the formation of cGAMP from GTP and ATP. The resultant cGAS-STING axis stimulates the production of inflammatory cytokines and type-I IFNs via activating the NF- $\kappa \mathrm{B}$ and IRF3, respectively [169]. Interestingly, tumor growth was augmented during radiotherapy in the mouse model lacking STING because of the attenuation of antitumor T-cell activation [170, 171]. In addition to it, tumoral growth was restricted in a murine melanoma model upon intratumoral administration of cGAMP [172]. Therefore, the cGAS/STING signaling pathway is an attractive therapeutic approach in inducing the efficient immune responses against tumors.

In another study, tumor cell-derived microparticles ( $\mathrm{T}$ MPs) were described to be used as cell-free tumor vaccine recently. T-MP-based vaccinations were found effective against several tumor types, and T-MP-loaded dendritic cells (DC) were also found very fruitful in a number of tumor models $[173,174]$. In these models, T-MPs efficiently delivered the DNA fragments to DCs that subsequently induced the expression of type I IFN via activating the cGAS/STING signaling pathway. Furthermore, the subsequent increase in the IFN level enhanced the antitumor immunity by promoting the presentation of tumor antigens to T-cells and maturation of DC. Indeed, this study represents a novel tumor cellfree vaccine strategy of high therapeutic potential [173].

\section{EVs as Cancer Biomarkers}

A substantial interest has been growing, in the past few years, in investigating the potential of tumor-associated EVs for diagnostic purposes and their exploitation for disease monitoring. EVs derived from a number of tumor types are believed to contain specific cargo including nucleic acid and various proteins [175]. The presence of tumor-derived EVs in circulating bodily fluids including cerebrospinal fluid (CSF), urine, and blood makes them an easy and readily accessible battery of biomarkers. Therefore, these tumorderived EVs are speculated to be specifically served for longitudinal disease monitoring and early relapse detection [176]. 
A few of EV-associated cargo (particularly nucleic acid and proteins) are also capable of predicting the therapeutic response of a specific treatment. Collectively, EVs have been proven by a growing body of evidence as a new representative class of rich and readily accessible cancer biomarkers. Their potential as a cancer biomarker was explored for the very first time by comparing the contents of EVs derived from glioblastoma and from the cells of origin [32]. In this report, authors found tumor-specific RNA and protein species, reflective of the parental cell, enriched in the released EVs [32]. Accordingly, a vast assortment of tumor-specific species including various nucleic acid species such as lncRNA [177], miRNA [178], and mRNA [32, 179] and multiple posttranslational protein modifications [179] have been well recognized. The diagnostic and predictive values of these EVs have been utilized in multiple studies with different cancer types and further strengthened recently by the massive profiling of sixty cancer cell lines [175]. EV proteome, from all the tested samples, was reported to reflect the cellular proteome and transcriptome. EV proteomic data helps in their exemplification by hierarchical clustering and categorization of the basis of the originating cell [175]. This correlation between tumor-associated EVs and contents of secreting cells is highly important for brain and CNS-associated tumors where conducting a tissue biopsy is a limitation. For instance, an upregulation of miR21 was observed in glioblastoma multiforme-associated EVs in CSF compared to healthy controls [180, 181]. Moreover, a positive correlation was noted between the level of EV-miR21 and tumor burden. Consequently, a huge number of tumor-derived EV-miRNA having prognostic and diagnostic values have been described in other types of cancer including pancreatic [182], colorectal [183], and non-small-cell lung [184] cancers. In line with it, several candidate mRNAs (C-MYC, BCL-6, and PTEN), characterized with diagnostic value to predict progressionfree survival, have been found in plasma-derived EVs from patients of non-Hodgkin's lymphoma [185]. Therefore, these reports have opened a new potential of tumor-associated EVs for noninvasive longitudinal disease monitoring [186]. The cancer-related EVs may also be helpful in early disease detection. For instance, it was shown in an in vivo pancreatic cancer model that particular EVs expressing a marker protein were upregulated even at the time when the tumor cannot be detected by conventional imaging techniques [187]. In addition to it, AML-EVs can be detected in the blood of acute myeloid leukemia (AML) patients even prior to the release of leukemic blasts in the blood [176]. Moreover, tumorassociated EVs have also been employed in the prediction of response to a specific treatment. Interestingly, tumorassociated EVs are capable of transferring resistance from drug-resistant to drug-sensitive cells via specific miRNAs and various protein species carried by them. Several therapies for a number of cancer types including pazopanib (chemotherapy) in soft tissue sarcoma [188], tamoxifen (antiestrogen) in breast cancer [189], and cetuximab (anti-EGFR) therapy in colon cancer [190] have been found to show the same resistance transfer phenomenon. Surprisingly, in all of these investigations, disruption of sensitivity to a specific drug and development of resistance were observed upon exposure to EVs from the resistant cells. Moreover, authors also illustrated a possible mechanism for Trastuzumab (anti-HER2) therapy in breast cancer [81]. Astonishingly, EV-associated HER2 was found to reduce the therapeutic effects of this drug as it is able to bind and decrease the available concentration of Trastuzumab [81]. Collectively, the above cited literature is suggestive of the prognostic, diagnostic, and predictive values of tumor-associated EVs [191].

Some of the potent EVs that have been recently found as potent biomarkers in different types of cancer are summarized in Table 3.

\section{Conclusion and Future Perspectives}

EVs are the potent carriers of cargo molecules including functional RNA species, many therapeutic agents like miRNAs, mRNAs, proteins, and peptides, and synthetic drugs. These small vesicles loaded with therapeutic agents are highly advantageous in terms of their biocompatibility, low immunogenicity, and innate ability to interact with target cells. Many futuristic approaches can be implicated from ex vivo and in vivo studies. However, due to complexity of EVs, many questions must be addressed prior to opting these molecules in clinics.

Advances in isolation and characterization techniques will allow more insight understanding and hence will provide a platform to develop EV-based therapeutic and diagnostic tools. An inexpensive, reliable method of isolations must be recognized and implemented to ensure that the optimal yield of EVs is being obtained in a safe and repeatable manner. Ultimately, a preferred method of isolating intact EVs must be identified and scaled so that EV-based options can be developed into a clinically viable therapy.

Upcoming research would completely get benefit of exosomes' ubiquitous occurrence in eukaryotic cells as they appear to provide an excess for anticancer therapy. Exosomes have been in attention for their role in the TME, and TDEs, in particular, provide a hopeful way for cancer remedies as mechanisms for superior drug delivery, tumor suppression, and immune regulation due to their appropriate dimension, composition, and homing capabilities. The progress of cancer encompasses the difficult and intricate communication of cells and signaling molecules in the TME, and exosomes have been shown to advance tumor growth through the inhibition of antitumor immunity and the development of angiogenesis.

Existing investigations in EVs are inadequate to the in vitro system. More in vivo studies must be conducted, like transgenic models of the breast cancer system, which helps us to have a better understanding of breast cancer cell-derived EVs. By in vivo imaging, we can know the source of EVs, their kinetics, numbers, the recipient cell types, and the even relationship between EVs and soluble factors. Efforts in this area to understand the biodistribution and bioavailability in vivo include elaborating the type and nature of interactions between EVs and the extracellular matrix and more pronounced in vivo models to test the relevance of in vitro observations. Improvement is being made here also, with growing 


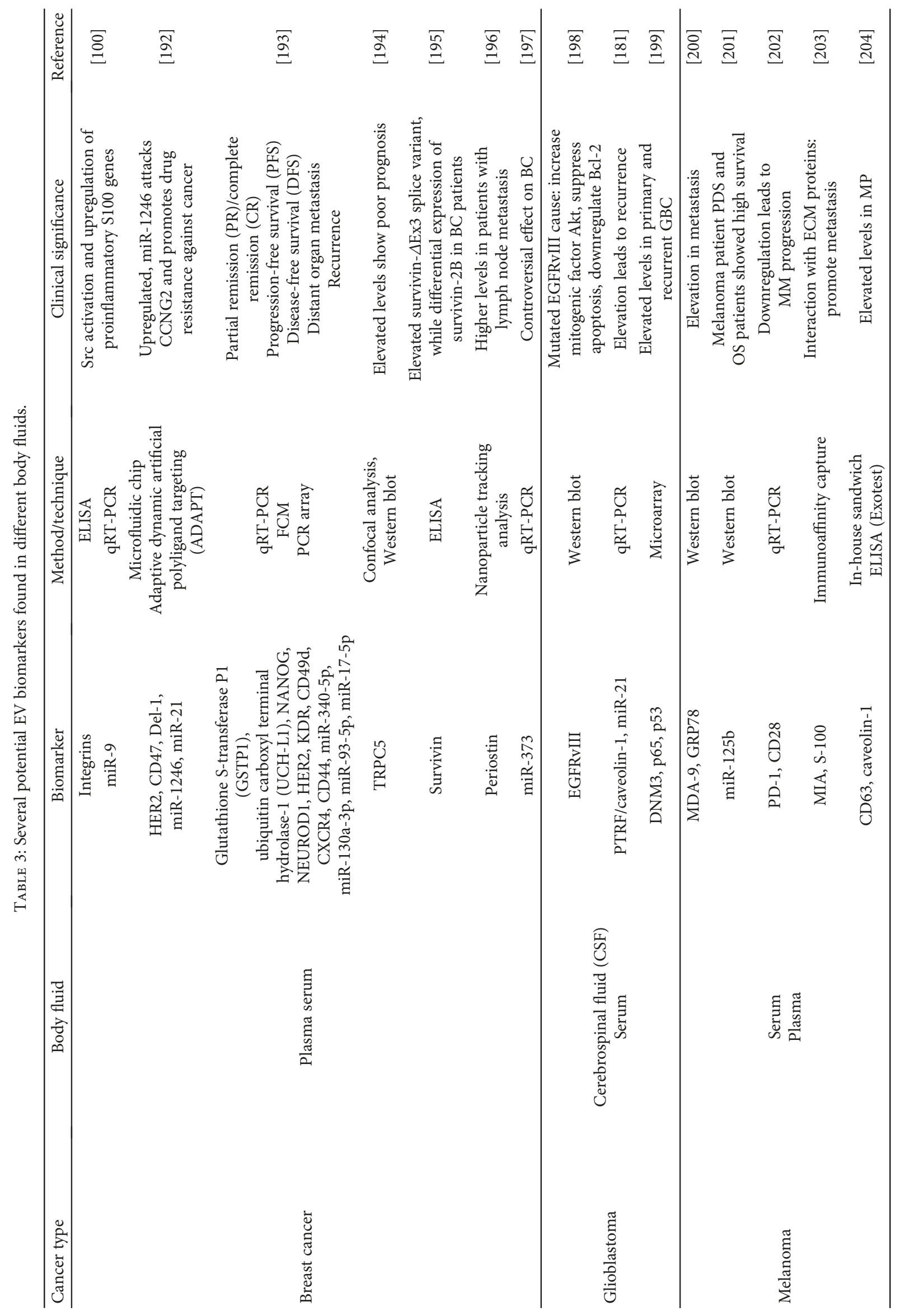




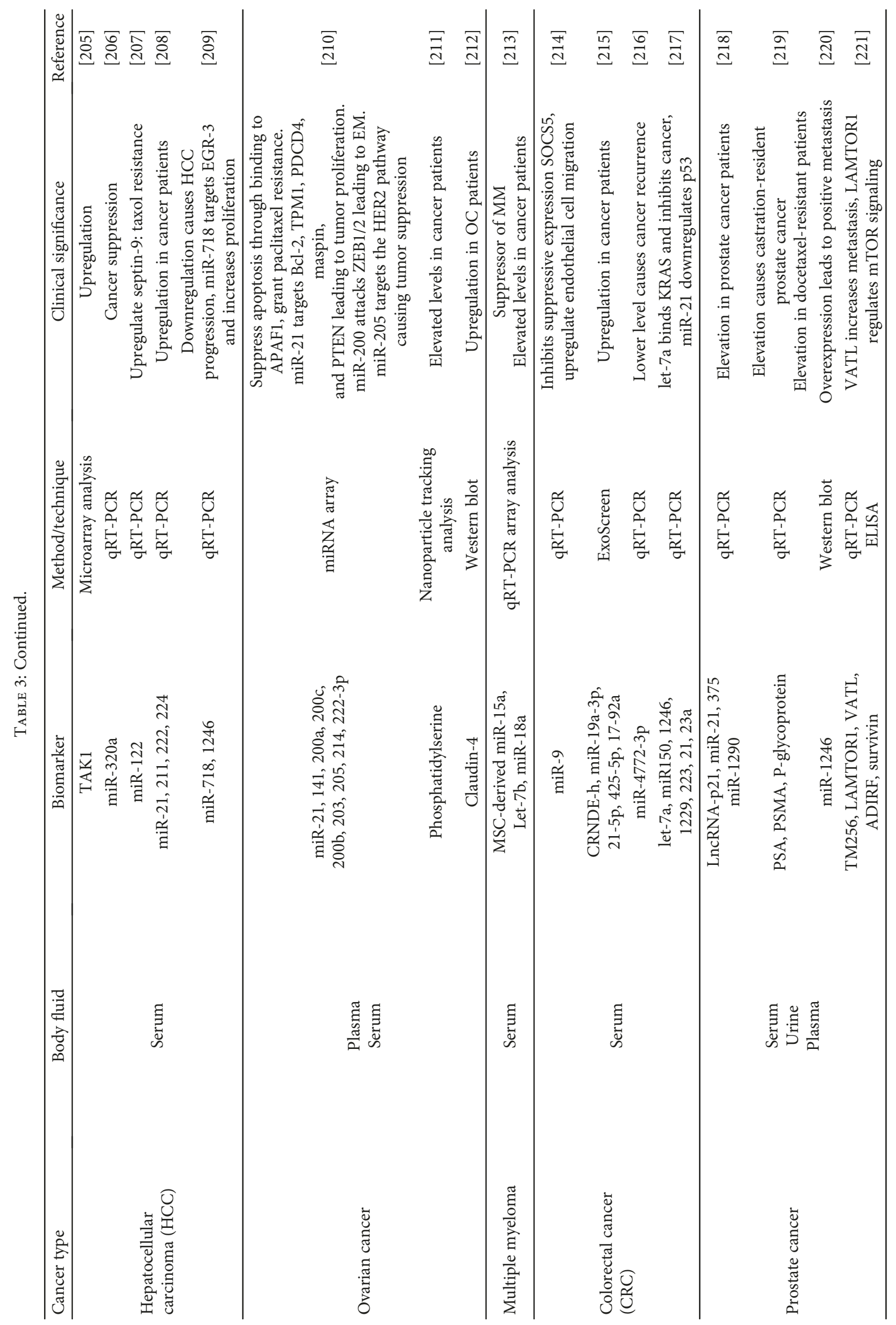




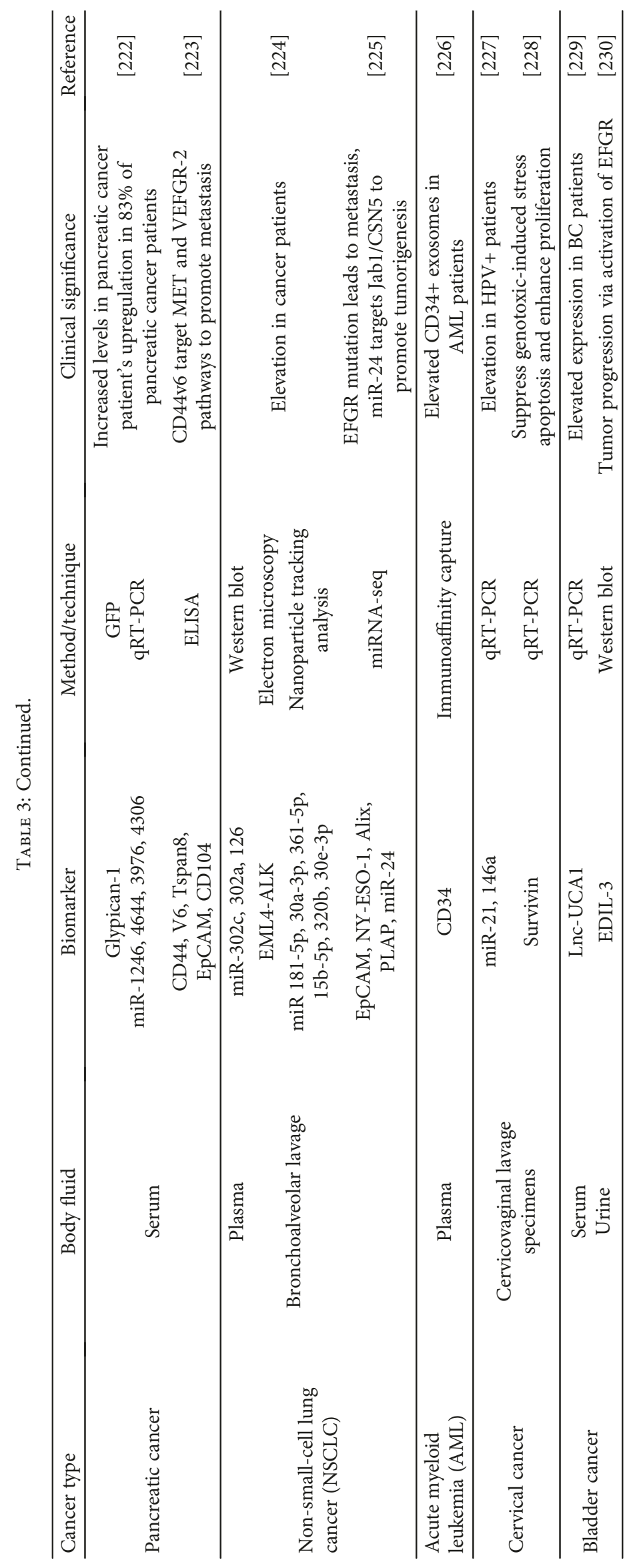


in vivo imaging techniques enabling visualization of EV production and distribution in vivo.

To develop EV-mediated therapeutic, efficient, and scalable bioengineering solutions are required; again, progress is being made, but there remain technical challenges. Given the pace of advances in the EV field over the past decade, it is likely that rapid progress will be made in addressing these challenges, and the promise of EV clinical translation will begin to become a reality. We hope that in the forthcoming years, research and trials can make available more efficient EV-based therapeutic options.

\section{Conflicts of Interest}

The authors declare no conflict of interests.

\section{Authors' Contributions}

Muhammad Babar Khawar and Muddasir Hassan Abbasi contributed equally to this work.

\section{Acknowledgments}

The authors are thankful to the Vice Chancellor, University of the Punjab, Lahore, Pakistan, for providing financial support for the accomplishment of this review.

\section{References}

[1] K. A. Ahmed and J. Xiang, "Mechanisms of cellular communication through intercellular protein transfer," Journal of Cellular and Molecular Medicine, vol. 15, no. 7, pp. 14581473, 2011.

[2] J. M. Pitt, G. Kroemer, and L. Zitvogel, "Extracellular vesicles: masters of intercellular communication and potential clinical interventions," The Journal of Clinical Investigation, vol. 126, no. 4, pp. 1139-1143, 2016.

[3] H. Peinado, S. Lavotshkin, and D. Lyden, "The secreted factors responsible for pre-metastatic niche formation: old sayings and new thoughts," Seminars in Cancer Biology, vol. 21, no. 2, pp. 139-146, 2011.

[4] R. Xu, D. W. Greening, H. J. Zhu, N. Takahashi, and R. J. Simpson, "Extracellular vesicle isolation and characterization: toward clinical application," The Journal of Clinical Investigation, vol. 126, no. 4, pp. 1152-1162, 2016.

[5] M. Colombo, G. Raposo, and C. Thery, "Biogenesis, secretion, and intercellular interactions of exosomes and other extracellular vesicles," Annual Review of Cell and Developmental Biology, vol. 30, no. 1, pp. 255-289, 2014.

[6] K. W. Witwer, E. I. Buzás, L. T. Bemis et al., "Standardization of sample collection, isolation and analysis methods in extracellular vesicle research," Journal of Extracellular Vesicles, vol. 2, no. 1, p. 20360, 2013.

[7] I. Parolini, C. Federici, C. Raggi et al., "Microenvironmental $\mathrm{pH}$ is a key factor for exosome traffic in tumor cells," Journal of Biological Chemistry, vol. 284, no. 49, pp. 34211-34222, 2009.

[8] M. Mittelbrunn, C. Gutiérrez-Vázquez, C. Villarroya-Beltri et al., "Unidirectional transfer of microRNA-loaded exosomes from T cells to antigen-presenting cells," Nature Communications, vol. 2, no. 1, article 282, 2011.
[9] Q. An, A. J. E. van Bel, and R. Hückelhoven, "Do plant cells secrete exosomes derived from multivesicular bodies?," Plant Signaling \& Behavior, vol. 2, no. 1, pp. 4-7, 2007.

[10] B. L. Deatherage and B. T. Cookson, "Membrane vesicle release in bacteria, eukaryotes, and archaea: a conserved yet underappreciated aspect of microbial life," Infection and Immunity, vol. 80, no. 6, pp. 1948-1957, 2012.

[11] F. Urabe, N. Kosaka, Y. Yoshioka, S. Egawa, and T. Ochiya, "The small vesicular culprits: the investigation of extracellular vesicles as new targets for cancer treatment," Clinical and Translational Medicine, vol. 6, no. 1, p. 45, 2017.

[12] K. Denzer, M. J. Kleijmeer, H. F. Heijnen, W. Stoorvogel, and H. J. Geuze, "Exosome: from internal vesicle of the multivesicular body to intercellular signaling device," Journal of Cell Science, vol. 113, Part 19, pp. 3365-3374, 2000.

[13] P. Wolf, "The nature and significance of platelet products in human plasma," British Journal of Haematology, vol. 13, no. 3, pp. 269-288, 1967.

[14] E. G. Trams, C. J. Lauter, J. Norman Salem, and U. Heine, "Exfoliation of membrane ecto-enzymes in the form of micro-vesicles," Biochimica et Biophysica Acta (BBA) - Biomembranes, vol. 645, no. 1, pp. 63-70, 1981.

[15] R. M. Johnstone, M. Adam, J. R. Hammond, L. Orr, and C. Turbide, "Vesicle formation during reticulocyte maturation. Association of plasma membrane activities with released vesicles (exosomes)," The Journal of Biological Chemistry, vol. 262, no. 19, pp. 9412-9420, 1987.

[16] R. Nair, L. Santos, S. Awasthi et al., "Extracellular vesicles derived from preosteoblasts influence embryonic stem cell differentiation," Stem Cells and Development, vol. 23, no. 14, pp. 1625-1635, 2014.

[17] F. Baixauli, C. López-Otín, and M. Mittelbrunn, "Exosomes and autophagy: coordinated mechanisms for the maintenance of cellular fitness," Frontiers in Immunology, vol. 5, p. $403,2014$.

[18] H. F. Heijnen, A. E. Schiel, R. Fijnheer, H. J. Geuze, and J. J. Sixma, "Activated platelets release two types of membrane vesicles: microvesicles by surface shedding and exosomes derived from exocytosis of multivesicular bodies and alpha-granules," Blood, vol. 94, no. 11, pp. 3791-3799, 1999.

[19] X. Teng, L. Chen, W. Chen, J. Yang, Z. Yang, and Z. Shen, "Mesenchymal stem cell-derived exosomes improve the microenvironment of infarcted myocardium contributing to angiogenesis and anti-inflammation," Cellular Physiology and Biochemistry, vol. 37, no. 6, pp. 24152424, 2015.

[20] D. W. Greening, S. K. Gopal, R. Xu, R. J. Simpson, and $\mathrm{W}$. Chen, "Exosomes and their roles in immune regulation and cancer," Seminars in Cell \& Developmental Biology, vol. 40, pp. 72-81, 2015.

[21] P. D. Robbins and A. E. Morelli, "Regulation of immune responses by extracellular vesicles," Nature Reviews Immunology, vol. 14, no. 3, pp. 195-208, 2014.

[22] M. D. Mitchell, H. N. Peiris, M. Kobayashi et al., "Placental exosomes in normal and complicated pregnancy," American Journal of Obstetrics and Gynecology, vol. 213, no. 4, Supplement, pp. S173-S181, 2015.

[23] D. W. Greening, H. P. T. Nguyen, K. Elgass, R. J. Simpson, and L. A. Salamonsen, "Human endometrial exosomes contain hormone-specific cargo modulating trophoblast 
adhesive capacity: insights into endometrial-embryo interactions," Biology of Reproduction, vol. 94, no. 2, pp. 1-15, 2016.

[24] C. Simon, D. W. Greening, D. Bolumar, N. Balaguer, L. A. Salamonsen, and F. Vilella, "Extracellular vesicles in human reproduction in health and disease," Endocrine Reviews, vol. 39, no. 3, pp. 292-332, 2018.

[25] C. Frühbeis, D. Fröhlich, W. P. Kuo et al., "Neurotransmittertriggered transfer of exosomes mediates oligodendrocyteneuron communication," PLoS Biology, vol. 11, no. 7, article e1001604, 2013.

[26] C. Fruhbeis, D. Frohlich, W. P. Kuo, and E. M. KramerAlbers, "Extracellular vesicles as mediators of neuron-glia communication," Frontiers in Cellular Neuroscience, vol. 7, p. 182, 2013.

[27] H. Peinado, H. Zhang, I. R. Matei et al., "Pre-metastatic niches: organ-specific homes for metastases," Nature Reviews Cancer, vol. 17, no. 5, pp. 302-317, 2017.

[28] S. L. N. Maas, X. O. Breakefield, and A. M. Weaver, "Extracellular vesicles: unique intercellular delivery vehicles," Trends in Cell Biology, vol. 27, no. 3, pp. 172-188, 2017.

[29] S. K. Gopal, D. W. Greening, A. Rai et al., "Extracellular vesicles: their role in cancer biology and epithelial-mesenchymal transition," Biochemical Journal, vol. 474, no. 1, pp. 21-45, 2017.

[30] V. Budnik, C. Ruiz-Canada, and F. Wendler, "Extracellular vesicles round off communication in the nervous system," Nature Reviews Neuroscience, vol. 17, no. 3, pp. 160-172, 2016.

[31] D. Hanahan and R. A. Weinberg, "Hallmarks of cancer: the next generation,” Cell, vol. 144, no. 5, pp. 646-674, 2011.

[32] J. Skog, T. Würdinger, S. van Rijn et al., "Glioblastoma microvesicles transport RNA and proteins that promote tumour growth and provide diagnostic biomarkers," Nature Cell Biology, vol. 10, no. 12, pp. 1470-1476, 2008.

[33] H. Peinado, M. Alečković, S. Lavotshkin et al., "Melanoma exosomes educate bone marrow progenitor cells toward a pro-metastatic phenotype through MET," Nature Medicine, vol. 18, no. 6, pp. 883-891, 2012.

[34] C. Théry, K. W. Witwer, E. Aikawa et al., "Minimal information for studies of extracellular vesicles 2018 (MISEV2018): a position statement of the International Society for Extracellular Vesicles and update of the MISEV2014 guidelines," Journal of Extracellular Vesicles, vol. 7, no. 1, article 1535750, 2018.

[35] G. Raposo and W. Stoorvogel, "Extracellular vesicles: exosomes, microvesicles, and friends," The Journal of Cell Biology, vol. 200, no. 4, pp. 373-383, 2013.

[36] J. Kowal, G. Arras, M. Colombo et al., "Proteomic comparison defines novel markers to characterize heterogeneous populations of extracellular vesicle subtypes," Proceedings of the National Academy of Sciences of the United States of America, vol. 113, no. 8, pp. E968-E977, 2016.

[37] N. P. Hessvik and A. Llorente, "Current knowledge on exosome biogenesis and release," Cellular and Molecular Life Sciences, vol. 75, no. 2, pp. 193-208, 2018.

[38] M. Yáñez-Mó, P. R. M. Siljander, Z. Andreu et al., "Biological properties of extracellular vesicles and their physiological functions," Journal of Extracellular Vesicles, vol. 4, no. 1, p. 27066, 2015.

[39] E. Cocucci and J. Meldolesi, "Ectosomes and exosomes: shedding the confusion between extracellular vesicles," Trends in Cell Biology, vol. 25, no. 6, pp. 364-372, 2015.
[40] E. Cocucci, G. Racchetti, and J. Meldolesi, "Shedding microvesicles: artefacts no more," Trends in Cell Biology, vol. 19, no. 2, pp. 43-51, 2009.

[41] C. D'Souza-Schorey and J. W. Clancy, "Tumor-derived microvesicles: shedding light on novel microenvironment modulators and prospective cancer biomarkers," Genes \& Development, vol. 26, no. 12, pp. 1287-1299, 2012.

[42] V. Muralidharan-Chari, J. W. Clancy, A. Sedgwick, and C. D'Souza-Schorey, "Microvesicles: mediators of extracellular communication during cancer progression," Journal of Cell Science, vol. 123, no. 10, pp. 1603-1611, 2010.

[43] O. Fourcade, M. F. Simon, C. Viodé et al., "Secretory phospholipase A2 generates the novel lipid mediator lysophosphatidic acid in membrane microvesicles shed from activated cells," Cell, vol. 80, no. 6, pp. 919-927, 1995.

[44] J. E. Fox, C. D. Austin, J. K. Boyles, and P. K. Steffen, "Role of the membrane skeleton in preventing the shedding of procoagulant-rich microvesicles from the platelet plasma membrane," The Journal of Cell Biology, vol. 111, no. 2, pp. 483-493, 1990.

[45] I. Del Conde, C. N. Shrimpton, P. Thiagarajan, and J. A. Lopez, "Tissue-factor-bearing microvesicles arise from lipid rafts and fuse with activated platelets to initiate coagulation," Blood, vol. 106, no. 5, pp. 1604-1611, 2005.

[46] R. F. Zwaal and E. M. Bevers, "Platelet phospholipid asymmetry and its significance in hemostasis," Subcellular Biochemistry, vol. 9, pp. 299-334, 1983.

[47] D. W. Dekkers, P. Comfurius, W. M. Vuist et al., "Impaired $\mathrm{Ca}^{2+}$-induced tyrosine phosphorylation and defective lipid scrambling in erythrocytes from a patient with Scott syndrome: a study using an inhibitor for scramblase that mimics the defect in Scott syndrome," Blood, vol. 91, no. 6, pp. 21332138, 1998.

[48] A. Piccin, W. G. Murphy, and O. P. Smith, "Circulating microparticles: pathophysiology and clinical implications," Blood Reviews, vol. 21, no. 3, pp. 157-171, 2007.

[49] Z. Beleznay, A. Zachowski, P. F. Devaux, M. P. Navazo, and P. Ott, "ATP-dependent aminophospholipid translocation in erythrocyte vesicles: stoichiometry of transport," Biochemistry, vol. 32, no. 12, pp. 3146-3152, 1993.

[50] V. Muralidharan-Chari, J. Clancy, C. Plou et al., "ARF6-regulated shedding of tumor cell-derived plasma membrane microvesicles," Current Biology, vol. 19, no. 22, pp. 18751885, 2009.

[51] B. Meehan, J. Rak, and D. Di Vizio, "Oncosomes - large and small: what are they, where they came from?," Journal of Extracellular Vesicles, vol. 5, no. 1, article 33109, 2016.

[52] V. R. Minciacchi, S. You, C. Spinelli et al., "Large oncosomes contain distinct protein cargo and represent a separate functional class of tumor-derived extracellular vesicles," Oncotarget, vol. 6, no. 13, pp. 11327-11341, 2015.

[53] D. di Vizio, M. Morello, A. C. Dudley et al., "Large oncosomes in human prostate cancer tissues and in the circulation of mice with metastatic disease," The American Journal of Pathology, vol. 181, no. 5, pp. 1573-1584, 2012.

[54] J. Van Deun, P. Mestdagh, R. Sormunen et al., "The impact of disparate isolation methods for extracellular vesicles on downstream RNA profiling," Journal of Extracellular Vesicles, vol. 3, no. 1, p. 24858, 2014.

[55] K. Rilla, H. Siiskonen, M. Tammi, and R. Tammi, "Chapter Five - Hyaluronan-coated extracellular vesicles-a novel link 
between hyaluronan and cancer," Advances in Cancer Research, vol. 123, pp. 121-148, 2014.

[56] H. G. Zhang, P. Cao, Y. Teng et al., "Isolation, identification, and characterization of novel nanovesicles," Oncotarget, vol. 7, no. 27, pp. 41346-41362, 2016.

[57] S. J. Gould and G. Raposo, "As we wait: coping with an imperfect nomenclature for extracellular vesicles," Journal of Extracellular Vesicles, vol. 2, no. 1, article 20389, 2013.

[58] I. Furi, F. Momen-Heravi, and G. Szabo, "Extracellular vesicle isolation: present and future," Annals of Translational Medicine, vol. 5, no. 12, p. 263, 2017.

[59] A. Bobrie, M. Colombo, S. Krumeich, G. Raposo, and C. Thery, "Diverse subpopulations of vesicles secreted by different intracellular mechanisms are present in exosome preparations obtained by differential ultracentrifugation," Journal of Extracellular Vesicles, vol. 1, no. 1, article 18397, 2012.

[60] E. Willms, H. J. Johansson, I. Mäger et al., "Cells release subpopulations of exosomes with distinct molecular and biological properties," Scientific Reports, vol. 6, no. 1, article 22519, 2016.

[61] S. Sarabipour, R. B. Chan, B. Zhou, G. Di Paolo, and K. Hristova, "Analytical characterization of plasma membrane-derived vesicles produced via osmotic and chemical vesiculation," Biochimica et Biophysica Acta (BBA) - Biomembranes, vol. 1848, no. 7, pp. 1591-1598, 2015.

[62] E. Sezgin, H. J. Kaiser, T. Baumgart, P. Schwille, K. Simons, and I. Levental, "Elucidating membrane structure and protein behavior using giant plasma membrane vesicles," Nature Protocols, vol. 7, no. 6, pp. 1042-1051, 2012.

[63] N. Del Piccolo, J. Placone, L. He, S. C. Agudelo, and K. Hristova, "Production of plasma membrane vesicles with chloride salts and their utility as a cell membrane mimetic for biophysical characterization of membrane protein interactions," Analytical Chemistry, vol. 84, no. 20, pp. 86508655, 2012.

[64] T. Baumgart, A. T. Hammond, P. Sengupta et al., "Large-scale fluid/fluid phase separation of proteins and lipids in giant plasma membrane vesicles," Proceedings of the National Academy of Sciences of the United States of America, vol. 104, no. 9, pp. 3165-3170, 2007.

[65] I. Levental, F. J. Byfield, P. Chowdhury, F. Gai, T. Baumgart, and P. A. Janmey, "Cholesterol-dependent phase separation in cell-derived giant plasma-membrane vesicles," Biochemical Journal, vol. 424, no. 2, pp. 163-167, 2009.

[66] C. Schmitt, A. H. Lippert, N. Bonakdar, V. Sandoghdar, and L. M. Voll, "Compartmentalization and transport in synthetic vesicles," Frontiers in Bioengineering and Biotechnology, vol. 4, p. 19, 2016.

[67] Q. Lin and E. London, "Preparation of artificial plasma membrane mimicking vesicles with lipid asymmetry," PloS One, vol. 9, no. 1, article e87903, 2014.

[68] A. Akbarzadeh, R. Rezaei-Sadabady, S. Davaran et al., "Liposome: classification, preparation, and applications," Nanoscale Research Letters, vol. 8, no. 1, p. 102, 2013.

[69] T. M. Allen and P. R. Cullis, "Liposomal drug delivery systems: from concept to clinical applications," Advanced Drug Delivery Reviews, vol. 65, no. 1, pp. 36-48, 2013.

[70] D. M. Pegtel, L. Peferoen, and S. Amor, "Extracellular vesicles as modulators of cell-to-cell communication in the healthy and diseased brain," Philosophical Transactions of the Royal
Society B: Biological Sciences, vol. 369, no. 1652, article 20130516, 2014.

[71] C. Ciardiello, L. Cavallini, C. Spinelli et al., "Focus on extracellular vesicles: new frontiers of cell-to-cell communication in cancer," International Journal of Molecular Sciences, vol. 17, no. 2, p. 175, 2016.

[72] B. T. Kreger, A. L. Dougherty, K. S. Greene, R. A. Cerione, and M. A. Antonyak, "Microvesicle cargo and function changes upon induction of cellular transformation," Journal of Biological Chemistry, vol. 291, no. 38, pp. 19774-19785, 2016.

[73] N. Kosaka, Y. Yoshioka, Y. Fujita, and T. Ochiya, "Versatile roles of extracellular vesicles in cancer," The Journal of Clinical Investigation, vol. 126, no. 4, pp. 1163-1172, 2016.

[74] N. Kosaka, H. Iguchi, K. Hagiwara, Y. Yoshioka, F. Takeshita, and T. Ochiya, "Neutral sphingomyelinase 2 (nSMase2)dependent exosomal transfer of angiogenic microRNAs regulate cancer cell metastasis," Journal of Biological Chemistry, vol. 288, no. 15, pp. 10849-10859, 2013.

[75] A. Yokoi, Y. Yoshioka, Y. Yamamoto et al., "Malignant extracellular vesicles carrying $M M P 1$ mRNA facilitate peritoneal dissemination in ovarian cancer," Nature Communications, vol. 8, no. 1, article 14470, 2017.

[76] M. Ostrowski, N. B. Carmo, S. Krumeich et al., "Rab27a and Rab27b control different steps of the exosome secretion pathway," Nature Cell Biology, vol. 12, no. 1, pp. 19-30, 2010.

[77] M. F. Baietti, Z. Zhang, E. Mortier et al., "Syndecan-syntenin-ALIX regulates the biogenesis of exosomes," Nature Cell Biology, vol. 14, no. 7, pp. 677-685, 2012.

[78] K. Yuyama, H. Sun, S. Mitsutake, and Y. Igarashi, "Sphingolipid-modulated exosome secretion promotes clearance of amyloid- $\beta$ by microglia," Journal of Biological Chemistry, vol. 287, no. 14, pp. 10977-10989, 2012.

[79] S. Phuyal, N. P. Hessvik, T. Skotland, K. Sandvig, and A. Llorente, "Regulation of exosome release by glycosphingolipids and flotillins," The FEBS Journal, vol. 281, no. 9, pp. 2214-2227, 2014.

[80] A. M. Marleau, C. S. Chen, J. A. Joyce, and R. H. Tullis, "Exosome removal as a therapeutic adjuvant in cancer," Journal of Translational Medicine, vol. 10, no. 1, p. 134, 2012.

[81] V. Ciravolo, V. Huber, G. C. Ghedini et al., "Potential role of HER2-overexpressing exosomes in countering trastuzumabbased therapy," Journal of Cellular Physiology, vol. 227, no. 2, pp. 658-667, 2012.

[82] N. Nishida-Aoki, N. Tominaga, F. Takeshita, H. Sonoda, Y. Yoshioka, and T. Ochiya, "Disruption of circulating extracellular vesicles as a novel therapeutic strategy against cancer metastasis," Molecular Therapy, vol. 25, no. 1, pp. 181-191, 2017.

[83] K. J. McKelvey, K. L. Powell, A. W. Ashton, J. M. Morris, and S. A. McCracken, "Exosomes: mechanisms of uptake," Journal of Circulating Biomarkers, vol. 4, p. 7, 2015.

[84] L. A. Mulcahy, R. C. Pink, and D. R. F. Carter, "Routes and mechanisms of extracellular vesicle uptake," Journal of Extracellular Vesicles, vol. 3, no. 1, p. 24641, 2014.

[85] K. C. French, M. A. Antonyak, and R. A. Cerione, "Extracellular vesicle docking at the cellular port: extracellular vesicle binding and uptake," Seminars in Cell \& Developmental Biology, vol. 67, pp. 48-55, 2017.

[86] H. Costa Verdera, J. J. Gitz-Francois, R. M. Schiffelers, and P. Vader, "Cellular uptake of extracellular vesicles is mediated 
by clathrin-independent endocytosis and macropinocytosis," Journal of Controlled Release, vol. 266, pp. 100-108, 2017.

[87] D. J. Schneider, J. M. Speth, L. R. Penke, S. H. Wettlaufer, J. A. Swanson, and M. Peters-Golden, "Mechanisms and modulation of microvesicle uptake in a model of alveolar cell communication," Journal of Biological Chemistry, vol. 292, no. 51, pp. 20897-20910, 2017.

[88] A. E. Sedgwick and C. D'Souza-Schorey, "The biology of extracellular microvesicles," Traffic, vol. 19, no. 5, pp. 319327, 2018.

[89] H. C. Christianson, K. J. Svensson, T. H. van Kuppevelt, J. P. $\mathrm{Li}$, and M. Belting, "Cancer cell exosomes depend on cellsurface heparan sulfate proteoglycans for their internalization and functional activity," Proceedings of the National Academy of Sciences of the United States of America, vol. 110, no. 43, pp. 17380-17385, 2013.

[90] K. J. Svensson, H. C. Christianson, A. Wittrup et al., "Exosome uptake depends on ERK1/2-heat shock protein 27 signaling and lipid raft-mediated endocytosis negatively regulated by caveolin-1," Journal of Biological Chemistry, vol. 288, no. 24, pp. 17713-17724, 2013.

[91] T. Kawamoto, N. Ohga, K. Akiyama et al., "Tumor-derived microvesicles induce proangiogenic phenotype in endothelial cells via endocytosis," PloS One, vol. 7, no. 3, article e34045, 2012.

[92] Y. Zheng, C. Tu, J. Zhang, and J. Wang, "Inhibition of multiple myeloma-derived exosomes uptake suppresses the functional response in bone marrow stromal cell," International Journal of Oncology, vol. 54, no. 3, pp. 1061-1070, 2019.

[93] H. Ghazarian, B. Idoni, and S. B. Oppenheimer, "A glycobiology review: carbohydrates, lectins and implications in cancer therapeutics," Acta Histochemica, vol. 113, no. 3, pp. 236247, 2011.

[94] K. Ohtsubo and J. D. Marth, "Glycosylation in cellular mechanisms of health and disease," Cell, vol. 126, no. 5, pp. 855867, 2006.

[95] R. J. Sola and K. Griebenow, "Glycosylation of therapeutic proteins: an effective strategy to optimize efficacy," BioDrugs, vol. 24, no. 1, pp. 9-21, 2010.

[96] R. J. Solá and K. A. I. Griebenow, "Effects of glycosylation on the stability of protein pharmaceuticals," Journal of Pharmaceutical Sciences, vol. 98, no. 4, pp. 1223-1245, 2009.

[97] M. E. Hung and J. N. Leonard, "Stabilization of exosometargeting peptides via engineered glycosylation," Journal of Biological Chemistry, vol. 290, no. 13, pp. 8166-8172, 2015.

[98] K. Yuyama, H. Sun, S. Sakai et al., "Decreased amyloid- $\beta$ pathologies by intracerebral loading of glycosphingolipidenriched exosomes in Alzheimer model mice," Journal of Biological Chemistry, vol. 289, no. 35, pp. 24488-24498, 2014.

[99] Y. T. Sato, K. Umezaki, S. Sawada et al., "Engineering hybrid exosomes by membrane fusion with liposomes," Scientific Reports, vol. 6, no. 1, article 21933, 2016.

[100] A. Hoshino, B. Costa-Silva, T. L. Shen et al., "Tumour exosome integrins determine organotropic metastasis," Nature, vol. 527, no. 7578, pp. 329-335, 2015.

[101] A. Shimoda, Y. Tahara, S. I. Sawada, Y. Sasaki, and K. Akiyoshi, "Glycan profiling analysis using evanescentfield fluorescence-assisted lectin array: importance of sugar recognition for cellular uptake of exosomes from mesenchymal stem cells," Biochemical and Biophysical Research Communications, vol. 491, no. 3, pp. 701-707, 2017.
[102] T. Akagi, K. Kato, M. Kobayashi, N. Kosaka, T. Ochiya, and T. Ichiki, "On-chip immunoelectrophoresis of extracellular vesicles released from human breast cancer cells," PloS One, vol. 10, no. 4, article e0123603, 2015.

[103] C. Williams, F. Royo, O. Aizpurua-Olaizola et al., "Glycosylation of extracellular vesicles: current knowledge, tools and clinical perspectives," Journal of Extracellular Vesicles, vol. 7, no. 1, article 1442985, 2018.

[104] M. Tkach, J. Kowal, A. E. Zucchetti et al., "Qualitative differences in T-cell activation by dendritic cell-derived extracellular vesicle subtypes," The EMBO Journal, vol. 36, no. 20, pp. 3012-3028, 2017.

[105] R.van der Meel, M. H. A. M. Fens, P. Vader, W. W. van Solinge, O. Eniola-Adefeso, and R. M. Schiffelers, "Extracellular vesicles as drug delivery systems: lessons from the liposome field," Journal of Controlled Release, vol. 195, pp. 72-85, 2014.

[106] Y. Lee and D. H. Thompson, "Stimuli-responsive liposomes for drug delivery," Wiley Interdisciplinary Reviews: Nanomedicine and Nanobiotechnology, vol. 9, no. 5, article e1450, 2017.

[107] H.-I. Chang and M. K. Yeh, "Clinical development of liposome based drugs: formulation, characterization, and therapeutic efficacy," International Journal of Nanomedicine, vol. 7, pp. 49-60, 2012.

[108] S. M. van Dommelen, P. Vader, S. Lakhal et al., "Microvesicles and exosomes: opportunities for cell-derived membrane vesicles in drug delivery," Journal of Controlled Release, vol. 161, no. 2, pp. 635-644, 2012.

[109] S. el Andaloussi, S. Lakhal, I. Mäger, and M. J. A. Wood, "Exosomes for targeted siRNA delivery across biological barriers," Advanced Drug Delivery Reviews, vol. 65, no. 3, pp. 391-397, 2013.

[110] N. Kosaka, F. Takeshita, Y. Yoshioka et al., "Exosomal tumorsuppressive microRNAs as novel cancer therapy: "exocure" is another choice for cancer treatment," Advanced Drug Delivery Reviews, vol. 65, no. 3, pp. 376-382, 2013.

[111] L. Alvarez-Erviti, Y. Seow, H. F. Yin, C. Betts, S. Lakhal, and M. J. A. Wood, "Delivery of siRNA to the mouse brain by systemic injection of targeted exosomes," Nature Biotechnology, vol. 29, no. 4, pp. 341-345, 2011.

[112] Z. Lu, B. Zuo, R. Jing et al., "Dendritic cell-derived exosomes elicit tumor regression in autochthonous hepatocellular carcinoma mouse models," Journal of Hepatology, vol. 67, no. 4, pp. 739-748, 2017.

[113] M. Fareh, F. Almairac, L. Turchi et al., "Cell-based therapy using miR-302-367 expressing cells represses glioblastoma growth," Cell Death \& Disease, vol. 8, no. 3, article e2713, 2017.

[114] M. Hadla, S. Palazzolo, G. Corona et al., "Exosomes increase the therapeutic index of doxorubicin in breast and ovarian cancer mouse models," Nanomedicine, vol. 11, no. 18, pp. 2431-2441, 2016.

[115] M. Julsgaard, L. A. Christensen, P. R. Gibson et al., "Concentrations of adalimumab and infliximab in mothers and newborns, and effects on infection," Gastroenterology, vol. 151, no. 1, pp. 110-119, 2016.

[116] M. Karin, "NF- $\kappa$ B as a critical link between inflammation and cancer," Cold Spring Harbor Perspectives in Biology, vol. 1, no. 5, article a000141, 2009.

[117] M. S. Kim, M. J. Haney, Y. Zhao et al., "Development of exosome-encapsulated paclitaxel to overcome MDR in 
cancer cells," Nanomedicine: Nanotechnology, Biology and Medicine, vol. 12, no. 3, pp. 655-664, 2016.

[118] T. Yang, P. Martin, B. Fogarty et al., "Exosome delivered anticancer drugs across the blood-brain barrier for brain cancer therapy in Danio Rerio," Pharmaceutical Research, vol. 32, no. 6, pp. 2003-2014, 2015.

[119] J. L. Munoz, S. A. Bliss, S. J. Greco, S. H. Ramkissoon, K. L. Ligon, and P. Rameshwar, "Delivery of functional anti-miR9 by mesenchymal stem cell-derived exosomes to glioblastoma multiforme cells conferred chemosensitivity," Molecular Therapy - Nucleic Acids, vol. 2, p. e126, 2013.

[120] M. J. Haney, N. L. Klyachko, Y. Zhao et al., "Exosomes as drug delivery vehicles for Parkinson's disease therapy," Journal of Controlled Release, vol. 207, pp. 18-30, 2015.

[121] C. J. D. Osterman, J. C. Lynch, P. Leaf et al., "Curcumin modulates pancreatic adenocarcinoma cell-derived exosomal function," PloS One, vol. 10, no. 7, article e0132845, 2015.

[122] X. Zhuang, X. Xiang, W. Grizzle et al., "Treatment of brain inflammatory diseases by delivering exosome encapsulated anti-inflammatory drugs from the nasal region to the brain," Molecular Therapy, vol. 19, no. 10, pp. 1769-1779, 2011.

[123] X. C. Jiang and J. Q. Gao, "Exosomes as novel bio-carriers for gene and drug delivery," International Journal of Pharmaceutics, vol. 521, no. 1-2, pp. 167-175, 2017.

[124] L. Barile and G. Vassalli, "Exosomes: therapy delivery tools and biomarkers of diseases," Pharmacology \& Therapeutics, vol. 174, pp. 63-78, 2017.

[125] H. Maeda, "Macromolecular therapeutics in cancer treatment: the EPR effect and beyond," Journal of Controlled Release, vol. 164, no. 2, pp. 138-144, 2012.

[126] G. Camussi, M. C. Deregibus, S. Bruno, C. Grange, V. Fonsato, and C. Tetta, "Exosome/microvesicle-mediated epigenetic reprogramming of cells," American Journal of Cancer Research, vol. 1, no. 1, pp. 98-110, 2011.

[127] C. Thery, M. Boussac, P. Veron et al., "Proteomic analysis of dendritic cell-derived exosomes: a secreted subcellular compartment distinct from apoptotic vesicles," The Journal of Immunology, vol. 166, no. 12, pp. 7309-7318, 2001.

[128] M. F. Bolukbasi, A. Mizrak, G. B. Ozdener et al., "miR1289 and "zipcode"-like sequence enrich mRNAs in microvesicles," Molecular Therapy - Nucleic Acids, vol. 1, p. e10, 2012.

[129] V. Gujrati, S. Kim, S. H. Kim et al., "Bioengineered bacterial outer membrane vesicles as cell-specific drug-delivery vehicles for cancer therapy," ACS Nano, vol. 8, no. 2, pp. 1525-1537, 2014.

[130] Y. Tian, S. Li, J. Song et al., "A doxorubicin delivery platform using engineered natural membrane vesicle exosomes for targeted tumor therapy," Biomaterials, vol. 35, no. 7, pp. 2383-2390, 2014.

[131] S. C. Jang, O. Y. Kim, C. M. Yoon et al., "Bioinspired exosome-mimetic nanovesicles for targeted delivery of chemotherapeutics to malignant tumors," ACS Nano, vol. 7, no. 9, pp. 7698-7710, 2013.

[132] E. J. Bunggulawa, W. Wang, T. Yin et al., "Recent advancements in the use of exosomes as drug delivery systems," Journal of Nanobiotechnology, vol. 16, no. 1, p. 81, 2018.

[133] K. Tang, Y. Zhang, H. Zhang et al., "Delivery of chemotherapeutic drugs in tumour cell-derived microparticles," Nature Communications, vol. 3, no. 1, article 1282, 2012.
[134] F. Guo, C. K. Chang, H. H. Fan et al., "Anti-tumour effects of exosomes in combination with cyclophosphamide and polyinosinic-polycytidylic acid," Journal of International Medical Research, vol. 36, no. 6, pp. 1342-1353, 2008.

[135] L. Pascucci, V. Coccè, A. Bonomi et al., "Paclitaxel is incorporated by mesenchymal stromal cells and released in exosomes that inhibit in vitro tumor growth: a new approach for drug delivery," Journal of Controlled Release, vol. 192, pp. 262270, 2014.

[136] H. Saari, E. Lazaro-Ibanez, T. Viitala, E. Vuorimaa-Laukkanen, P. Siljander, and M. Yliperttula, "Microvesicle- and exosome-mediated drug delivery enhances the cytotoxicity of Paclitaxel in autologous prostate cancer cells," Journal of Controlled Release, vol. 220, Part B, pp. 727-737, 2015.

[137] N. Seo, Y. Shirakura, Y. Tahara et al., "Activated CD8 ${ }^{+}$T cell extracellular vesicles prevent tumour progression by targeting of lesional mesenchymal cells," Nature Communications, vol. 9, no. 1, article 435, 2018.

[138] M. B. Huang, R. R. Gonzalez, J. Lillard, and V. C. Bond, "Secretion modification region-derived peptide blocks exosome release and mediates cell cycle arrest in breast cancer cells," Oncotarget, vol. 8, no. 7, pp. 11302-11315, 2017.

[139] S. Yu, C. Liu, K. Su et al., "Tumor exosomes inhibit differentiation of bone marrow dendritic cells," The Journal of Immunology, vol. 178, no. 11, pp. 6867-6875, 2007.

[140] F. Chalmin, S. Ladoire, G. Mignot et al., "Membrane-associated Hsp72 from tumor-derived exosomes mediates STAT3-dependent immunosuppressive function of mouse and human myeloid-derived suppressor cells," The Journal of Clinical Investigation, vol. 120, no. 2, pp. 457-471, 2010.

[141] N. A. Atai, L. Balaj, H. van Veen et al., "Heparin blocks transfer of extracellular vesicles between donor and recipient cells," Journal of Neuro-Oncology, vol. 115, no. 3, pp. 343351, 2013.

[142] A. Datta, H. Kim, M. Lal et al., "Manumycin A suppresses exosome biogenesis and secretion via targeted inhibition of Ras/Raf/ERK1/2 signaling and hnRNP H1 in castrationresistant prostate cancer cells," Cancer Letters, vol. 408, pp. 73-81, 2017.

[143] S. Kamerkar, V. S. LeBleu, H. Sugimoto et al., "Exosomes facilitate therapeutic targeting of oncogenic KRAS in pancreatic cancer," Nature, vol. 546, no. 7659, pp. 498-503, 2017.

[144] M. Tkach and C. Thery, "Communication by extracellular vesicles: where we are and where we need to go," Cell, vol. 164, no. 6, pp. 1226-1232, 2016.

[145] J. M. Pitt, F. Andre, S. Amigorena et al., "Dendritic cellderived exosomes for cancer therapy," The Journal of Clinical Investigation, vol. 126, no. 4, pp. 1224-1232, 2016.

[146] R. S. Conlan, S. Pisano, M. I. Oliveira, M. Ferrari, and I. Mendes Pinto, "Exosomes as reconfigurable therapeutic systems," Trends in Molecular Medicine, vol. 23, no. 7, pp. 636-650, 2017.

[147] N. L. Syn, L. Wang, E. K.-H. Chow, C. T. Lim, and B. C. Goh, "Exosomes in cancer nanomedicine and immunotherapy: prospects and challenges," Trends in Biotechnology, vol. 35, no. 7, pp. 665-676, 2017.

[148] K. Shimbo, S. Miyaki, H. Ishitobi et al., "Exosome-formed synthetic microRNA-143 is transferred to osteosarcoma cells and inhibits their migration," Biochemical and Biophysical Research Communications, vol. 445, no. 2, pp. 381-387, 2014. 
[149] A. T. Jan, S. Rahman, S. Khan, S. A. Tasduq, and I. Choi, "Biology, pathophysiological role, and clinical implications of exosomes: a critical appraisal," Cells, vol. 8, no. 2, p. 99, 2019.

[150] K. Kunigelis and M. Graner, "The dichotomy of tumor exosomes (TEX) in cancer immunity: is it all in the ConTEXt?," Vaccines, vol. 3, no. 4, pp. 1019-1051, 2015.

[151] M. W. Graner, O. Alzate, A. M. Dechkovskaia et al., "Proteomic and immunologic analyses of brain tumor exosomes," The FASEB Journal, vol. 23, no. 5, pp. 1541-1557, 2009.

[152] S. G. Griffiths, M. T. Cormier, A. Clayton, and A. A. Doucette, "Differential proteome analysis of extracellular vesicles from breast cancer cell lines by chaperone affinity enrichment," Proteomes, vol. 5, no. 4, p. 25, 2017.

[153] J. Wolfers, A. Lozier, G. Raposo et al., "Tumor-derived exosomes are a source of shared tumor rejection antigens for CTL cross-priming," Nature Medicine, vol. 7, no. 3, pp. 297-303, 2001.

[154] S. L. Altieri, A. N. H. Khan, and T. B. Tomasi, "Exosomes from plasmacytoma cells as a tumor vaccine," Journal of Immunotherapy, vol. 27, no. 4, pp. 282-288, 2004.

[155] T. L. Whiteside, "Exosomes in cancer: another mechanism of tumor-induced immune suppression," in Tumor Immune Microenvironment in Cancer Progression and Cancer Ther$a p y$, P. Kalinski, Ed., vol. 1036 of Advances in Experimental Medicine and Biology, pp. 81-89, Springer, Cham, 2017.

[156] L. Czernek and M. Duchler, "Functions of cancer-derived extracellular vesicles in immunosuppression," Archivum Immunologiae et Therapiae Experimentalis, vol. 65, no. 4, pp. 311-323, 2017.

[157] S. Dai, D. Wei, Z. Wu et al., "Phase I clinical trial of autologous ascites-derived exosomes combined with GM-CSF for colorectal cancer," Molecular Therapy, vol. 16, no. 4, pp. 782-790, 2008.

[158] D. W. Andrews, M. Resnicoff, A. E. Flanders et al., "Results of a pilot study involving the use of an antisense oligodeoxynucleotide directed against the insulin-like growth factor type I receptor in malignant astrocytomas," Journal of Clinical Oncology, vol. 19, no. 8, pp. 2189-2200, 2001.

[159] L. A. Harshyne, K. M. Hooper, E. G. Andrews et al., "Glioblastoma exosomes and IGF-1R/AS-ODN are immunogenic stimuli in a translational research immunotherapy paradigm," Cancer Immunology, Immunotherapy, vol. 64, no. 3, pp. 299-309, 2015.

[160] B. Besse, M. Charrier, V. Lapierre et al., "Dendritic cellderived exosomes as maintenance immunotherapy after first line chemotherapy in NSCLC," OncoImmunology, vol. 5, no. 4, article e1071008, 2015.

[161] B. Escudier, T. Dorval, N. Chaput et al., "Vaccination of metastatic melanoma patients with autologous dendritic cell (DC) derived-exosomes: results of thefirst phase I clinical trial," Journal of Translational Medicine, vol. 3, no. 1, p. 10, 2005.

[162] W. Chen, J. Jiang, W. Xia, and J. Huang, “Tumor-related exosomes contribute to tumor-promoting microenvironment: an immunological perspective," Journal of Immunology Research, vol. 2017, Article ID 1073947, 10 pages, 2017.

[163] T. L. Whiteside, "Exosomes carrying immunoinhibitory proteins and their role in cancer," Clinical \& Experimental Immunology, vol. 189, no. 3, pp. 259-267, 2017.
[164] T. L. Whiteside, "Exosomes and tumor-mediated immune suppression," The Journal of Clinical Investigation, vol. 126, no. 4, pp. 1216-1223, 2016.

[165] X. Qu, Y. Tang, and S. Hua, "Immunological approaches towards cancer and inflammation: a cross talk," Frontiers in Immunology, vol. 9, p. 563, 2018.

[166] M. Idzko, D. Ferrari, and H. K. Eltzschig, "Nucleotide signalling during inflammation," Nature, vol. 509, no. 7500, pp. 310-317, 2014.

[167] S. Roger, B. Jelassi, I. Couillin, P. Pelegrin, P. Besson, and L. H. Jiang, "Understanding the roles of the P2X7 receptor in solid tumour progression and therapeutic perspectives," Biochimica et Biophysica Acta (BBA) - Biomembranes, vol. 1848, no. 10, pp. 2584-2602, 2015.

[168] M. W. Graner, "Extracellular vesicles in cancer immune responses: roles of purinergic receptors," Seminars in Immunopathology, vol. 40, no. 5, pp. 465-475, 2018.

[169] X. Cai, Y. H. Chiu, and Z. J. Chen, "The cGAS-cGAMPSTING pathway of cytosolic DNA sensing and signaling," Molecular Cell, vol. 54, no. 2, pp. 289-296, 2014.

[170] S. R. Woo, M. B. Fuertes, L. Corrales et al., "STING-dependent cytosolic DNA sensing mediates innate immune recognition of immunogenic tumors," Immunity, vol. 41, no. 5, pp. 830-842, 2014.

[171] L. Deng, H. Liang, M. Xu et al., "STING-dependent cytosolic DNA sensing promotes radiation-induced type I interferondependent antitumor immunity in immunogenic tumors," Immunity, vol. 41, no. 5, pp. 843-852, 2014.

[172] O. Demaria, A. de Gassart, S. Coso et al., "STING activation of tumor endothelial cells initiates spontaneous and therapeutic antitumor immunity," Proceedings of the National Academy of Sciences of the United States of America, vol. 112, no. 50, pp. 15408-15413, 2015.

[173] H. Zhang, K. Tang, Y. Zhang et al., "Cell-free tumor microparticle vaccines stimulate dendritic cells via cGAS/STING signaling," Cancer Immunology Research, vol. 3, no. 2, pp. 196-205, 2015.

[174] H. Zhang and B. Huang, "Tumor cell-derived microparticles: a new form of cancer vaccine," OncoImmunology, vol. 4, no. 8, article e1017704, 2015.

[175] S. N. Hurwitz, M. A. Rider, J. L. Bundy, X. Liu, R. K. Singh, and D. G. Meckes Jr., "Proteomic profiling of NCI-60 extracellular vesicles uncovers common protein cargo and cancer type-specific biomarkers," Oncotarget, vol. 7, no. 52, pp. 86999-87015, 2016.

[176] N. I. Hornick, J. Huan, B. Doron et al., "Serum exosome microRNA as a minimally-invasive early biomarker of AML," Scientific Reports, vol. 5, no. 1, article 11295, 2015.

[177] T. Kogure, I. K. Yan, W. L. Lin, and T. Patel, "Extracellular vesicle-mediated transfer of a novel long noncoding RNA TUC339: a mechanism of intercellular signaling in human hepatocellular cancer," Genes \& Cancer, vol. 4, no. 7-8, pp. 261-272, 2013.

[178] G. Rabinowits, C. Gercel-Taylor, J. M. Day, D. D. Taylor, and G. H. Kloecker, "Exosomal microRNA: a diagnostic marker for lung cancer," Clinical Lung Cancer, vol. 10, no. 1, pp. 42-46, 2009.

[179] I. H. Chen, L. Xue, C. C. Hsu et al., "Phosphoproteins in extracellular vesicles as candidate markers for breast cancer," Proceedings of the National Academy of Sciences of the United States of America, vol. 114, no. 12, pp. 3175-3180, 2017. 
[180] J. C. Akers, V. Ramakrishnan, R. Kim et al., "miR-21 in the extracellular vesicles (EVs) of cerebrospinal fluid (CSF): a platform for glioblastoma biomarker development," PloS One, vol. 8, no. 10, article e78115, 2013.

[181] R. Shi, P. Y. Wang, X. Y. Li et al., "Exosomal levels of miRNA21 from cerebrospinal fluids associated with poor prognosis and tumor recurrence of glioma patients," Oncotarget, vol. 6, no. 29, pp. 26971-26981, 2015.

[182] T. Goto, M. Fujiya, H. Konishi et al., "An elevated expression of serum exosomal microRNA-191, -21,-451a of pancreatic neoplasm is considered to be efficient diagnostic marker," BMC Cancer, vol. 18, no. 1, p. 116, 2018.

[183] F. Fu, W. Jiang, L. Zhou, and Z. Chen, "Circulating exosomal miR-17-5p and miR-92a-3p predict pathologic stage and grade of colorectal cancer," Translational oncology, vol. 11, no. 2, pp. 221-232, 2018.

[184] Q. Liu, Z. Yu, S. Yuan et al., "Circulating exosomal microRNAs as prognostic biomarkers for non-small-cell lung cancer," Oncotarget, vol. 8, no. 8, pp. 13048-13058, 2017.

[185] M. Provencio, M. Rodríguez, B. Cantos et al., "mRNA in exosomas as a liquid biopsy in non-Hodgkin lymphoma: a multicentric study by the Spanish Lymphoma Oncology Group," Oncotarget, vol. 8, no. 31, pp. 50949-50957, 2017.

[186] T. L. Whiteside, "The potential of tumor-derived exosomes for noninvasive cancer monitoring," Expert Review of Molecular Diagnostics, vol. 15, no. 10, pp. 1293-1310, 2015.

[187] S. A. Melo, L. B. Luecke, C. Kahlert et al., "Glypican-1 identifies cancer exosomes and detects early pancreatic cancer," Nature, vol. 523, no. 7559, pp. 177-182, 2015.

[188] K. Shiozawa, J. Shuting, Y. Yoshioka, T. Ochiya, and T. Kondo, "Extracellular vesicle-encapsulated microRNA761 enhances pazopanib resistance in synovial sarcoma," Biochemical and Biophysical Research Communications, vol. 495, no. 1, pp. 1322-1327, 2018.

[189] Y. Wei, X. Lai, S. Yu et al., "Exosomal miR-221/222 enhances tamoxifen resistance in recipient ER-positive breast cancer cells," Breast Cancer Research and Treatment, vol. 147, no. 2, pp. 423-431, 2014.

[190] S. Zhang, Y. Zhang, J. Qu et al., "Exosomes promote cetuximab resistance via the PTEN/Akt pathway in colon cancer cells," Brazilian Journal of Medical and Biological Research, vol. 51, no. 1, 2018.

[191] R. E. Lane, D. Korbie, M. M. Hill, and M. Trau, "Extracellular vesicles as circulating cancer biomarkers: opportunities and challenges," Clinical and Translational Medicine, vol. 7, no. 1, p. 14, 2018.

[192] L. Gerratana, B. Toffoletto, M. Bulfoni et al., "A37Metastatic breast cancer and circulating exosomes. Hints from an exploratory analysis," Annals of Oncology, vol. 26, Supplement 6, pp. vi14.3-vivi14, 2015.

[193] B. C. Melnik and G. Schmitz, "Exosomes of pasteurized milk: potential pathogens of Western diseases," Journal of Translational Medicine, vol. 17, no. 1, p. 3, 2019.

[194] T. Wang, K. Ning, T. Lu et al., "Increasing circulating exosomes-carrying TRPC5 predicts chemoresistance in metastatic breast cancer patients," Cancer Science, vol. 108, no. 3, pp. 448-454, 2017.

[195] I. Vardaki, S. Ceder, D. Rutishauser, G. Baltatzis, T. Foukakis, and T. Panaretakis, "Periostin is identified as a putative metastatic marker in breast cancer-derived exosomes," Oncotarget, vol. 7, no. 46, pp. 74966-74978, 2016.
[196] S. Khan, H. F. Bennit, D. Turay et al., "Early diagnostic value of survivin and its alternative splice variants in breast cancer," BMC Cancer, vol. 14, no. 1, p. 176, 2014.

[197] C. Eichelser, I. Stuckrath, V. Muller et al., "Increased serum levels of circulating exosomal microRNA-373 in receptornegative breast cancer patients," Oncotarget, vol. 5, no. 20, pp. 9650-9663, 2014.

[198] H. Xu, H. Zong, C. Ma et al., "Epidermal growth factor receptor in glioblastoma," Oncology Letters, vol. 14, no. 1, pp. 512516, 2017.

[199] J. K. Yang, J. Song, H. R. Huo et al., “DNM3, p65 and p53 from exosomes represent potential clinical diagnosis markers for glioblastoma multiforme," Therapeutic Advances in Medical Oncology, vol. 9, no. 12, pp. 741-754, 2017.

[200] X. Ma, W. Guo, S. Yang, X. Zhu, J. Xiang, and H. Li, “Serum GRP78 as a tumor marker and its prognostic significance in non-small cell lung cancers: a retrospective study," Disease Markers, vol. 2015, Article ID 814670, 6 pages, 2015.

[201] E. Alegre, M. F. Sanmamed, C. Rodriguez, O. Carranza, S. Martín-Algarra, and Á. González, "Study of circulating microRNA-125b levels in serum exosomes in advanced melanoma," Archives of Pathology \& Laboratory Medicine, vol. 138, no. 6, pp. 828-832, 2014.

[202] M. Tucci, A. Passarelli, F. Mannavola et al., "Serum exosomes as predictors of clinical response to ipilimumab in metastatic melanoma," OncoImmunology, vol. 7, no. 2, article e1387706, 2018.

[203] A. K. Bosserhoff and R. Buettner, "Expression, function and clinical relevance of MIA (melanoma inhibitory activity)," Histology and Histopathology, vol. 17, no. 1, pp. 289-300, 2002.

[204] M. Logozzi, A. de Milito, L. Lugini et al., "High levels of exosomes expressing CD63 and caveolin-1 in plasma of melanoma patients," PloS One, vol. 4, no. 4, article e5219, 2009.

[205] H. L. Sun, R. Cui, J. K. Zhou et al., "ERK activation globally downregulates miRNAs through phosphorylating exportin5," Cancer Cell, vol. 30, no. 5, pp. 723-736, 2016.

[206] H. Wang, L. Hou, A. Li, Y. Duan, H. Gao, and X. Song, "Expression of serum exosomal microRNA-21 in human hepatocellular carcinoma," BioMed Research International, vol. 2014, Article ID 864894, 5 pages, 2014.

[207] W. Sohn, J. Kim, S. H. Kang et al., "Serum exosomal microRNAs as novel biomarkers for hepatocellular carcinoma," Experimental \& Molecular Medicine, vol. 47, no. 9, article e184, 2015.

[208] K. Sugimachi, T. Matsumura, H. Hirata et al., "Identification of a bona fide microRNA biomarker in serum exosomes that predicts hepatocellular carcinoma recurrence after liver transplantation," British Journal of Cancer, vol. 112, no. 3, pp. 532-538, 2015.

[209] Z.-d. Wang, F.-y. Qu, Y.-y. Chen, Z.-s. Ran, H.-y. Liu, and H.-d. Zhang, "Involvement of microRNA-718, a new regulator of EGR3, in regulation of malignant phenotype of HCC cells," Journal of Zhejiang University-SCIENCE B, vol. 18, no. 1, pp. 27-36, 2017.

[210] C. L. Au Yeung, N. N. Co, T. Tsuruga et al., "Exosomal transfer of stroma-derived miR21 confers paclitaxel resistance in ovarian cancer cells through targeting APAF1," Nature Communications, vol. 7, no. 1, article 11150, 2016. 
[211] D. D. Taylor and C. Gercel-Taylor, "MicroRNA signatures of tumor-derived exosomes as diagnostic biomarkers of ovarian cancer," Gynecologic Oncology, vol. 110, no. 1, pp. 13-21, 2008.

[212] J. Li, C. A. Sherman-Baust, M. Tsai-Turton, R. E. Bristow, R. B. Roden, and P. J. Morin, "Claudin-containing exosomes in the peripheral circulation of women with ovarian cancer," BMC Cancer, vol. 9, no. 1, p. 244, 2009.

[213] S. Manier, C. J. Liu, H. Avet-Loiseau et al., "Prognostic role of circulating exosomal miRNAs in multiple myeloma," Blood, vol. 129, no. 17, pp. 2429-2436, 2017.

[214] W. Guo, Y. Gao, N. Li et al., "Exosomes: new players in cancer (Review)," Oncology Reports, vol. 38, no. 2, pp. 665-675, 2017.

[215] M. Zhu, Z. Huang, D. Zhu et al., "A panel of microRNA signature in serum for colorectal cancer diagnosis," Oncotarget, vol. 8, no. 10, pp. 17081-17091, 2017.

[216] C. Liu, C. Eng, J. Shen et al., "Serum exosomal miR-4772-3p is a predictor of tumor recurrence in stage II and III colon cancer," Oncotarget, vol. 7, no. 46, pp. 76250-76260, 2016.

[217] M. Agostini, S. Pucciarelli, F. Calore, C. Bedin, M. Enzo, and D. Nitti, "miRNAs in colon and rectal cancer: a consensus for their true clinical value," Clinica Chimica Acta, vol. 411, no. 17-18, pp. 1181-1186, 2010.

[218] M. Işın, E. Uysaler, E. Özgür et al., "Exosomal lncRNA-p21 levels may help to distinguish prostate cancer from benign disease," Frontiers in Genetics, vol. 6, p. 168, 2015.

[219] T. Kato, K. Mizutani, K. Kameyama et al., "Serum exosomal P-glycoprotein is a potential marker to diagnose docetaxel resistance and select a taxoid for patients with prostate cancer," Urologic Oncology: Seminars and Original Investigations, vol. 33, no. 9, pp. 385.e15-385.e20, 2015.

[220] D. Bhagirath, T. L. Yang, N. Bucay et al., "MicroRNA-1246 is an exosomal biomarker for aggressive prostate cancer," Cancer Research, vol. 78, no. 7, pp. 1833-1844, 2018.

[221] Q. Yang, M. P. Diamond, and A. Al-Hendy, "The emerging role of extracellular vesicle-derived miRNAs: implication in cancer progression and stem cell related diseases," Journal of Clinical Epigenetics, vol. 2, no. 1, 2016.

[222] B. Madhavan, S. Yue, U. Galli et al., "Combined evaluation of a panel of protein and miRNA serum-exosome biomarkers for pancreatic cancer diagnosis increases sensitivity and specificity," International Journal of Cancer, vol. 136, no. 11, pp. 2616-2627, 2015.

[223] A. Matzke-Ogi, K. Jannasch, M. Shatirishvili et al., "Inhibition of tumor growth and metastasis in pancreatic cancer models by interference with CD44v6 signaling," Gastroenterology, vol. 150, no. 2, pp. 513-525.e10, 2016.

[224] M. Rodríguez, J. Silva, A. López-Alfonso et al., "Different exosome cargo from plasma/bronchoalveolar lavage in nonsmall-cell lung cancer," Genes, Chromosomes and Cancer, vol. 53, no. 9, pp. 713-724, 2014.

[225] E. Brambilla and A. Gazdar, "Pathogenesis of lung cancer signalling pathways: roadmap for therapies," European Respiratory Journal, vol. 33, no. 6, pp. 1485-1497, 2009.

[226] C. S. Hong, L. Muller, M. Boyiadzis, and T. L. Whiteside, "Isolation and characterization of CD34+ blast-derived exosomes in acute myeloid leukemia," PloS One, vol. 9, no. 8, article e103310, 2014.
[227] Z. Zhao, D. C. Muth, K. Mulka et al., "miRNA profiling of primate cervicovaginal lavage and extracellular vesicles reveals miR-186-5p as a potential retroviral restriction factor in macrophages," January 2018, bioRxiv: 263947.

[228] S. Khan, J. R. Aspe, M. G. Asumen et al., "Extracellular, cellpermeable survivin inhibits apoptosis while promoting proliferative and metastatic potential," British Journal of Cancer, vol. 100, no. 7, pp. 1073-1086, 2009.

[229] M. Xue, W. Chen, A. Xiang et al., "Hypoxic exosomes facilitate bladder tumor growth and development through transferring long non-coding RNA-UCA1," Molecular Cancer, vol. 16, no. 1, p. 143, 2017.

[230] C. J. Beckham, J. Olsen, P. N. Yin et al., "Bladder cancer exosomes contain EDIL-3/Del1 and facilitate cancer progression," The Journal of Urology, vol. 192, no. 2, pp. 583-592, 2014. 


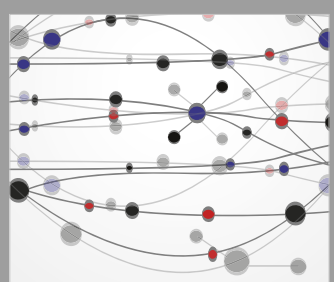

The Scientific World Journal
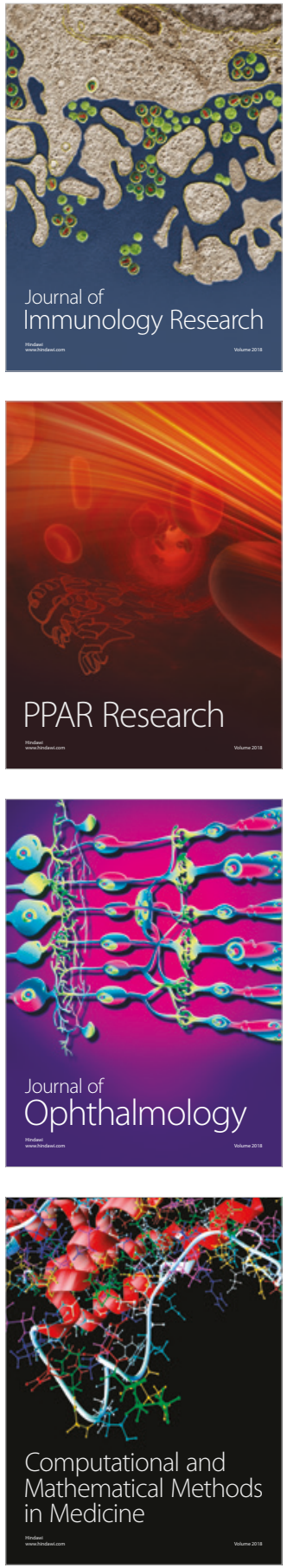

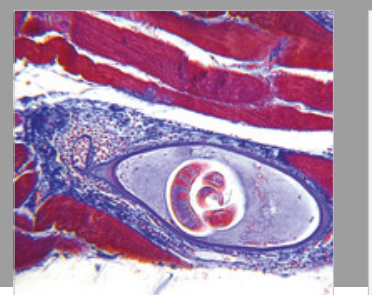

Gastroenterology Research and Practice

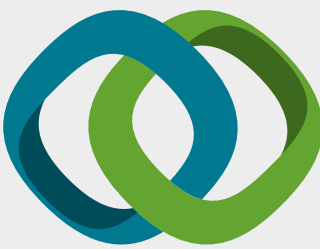

\section{Hindawi}

Submit your manuscripts at

www.hindawi.com
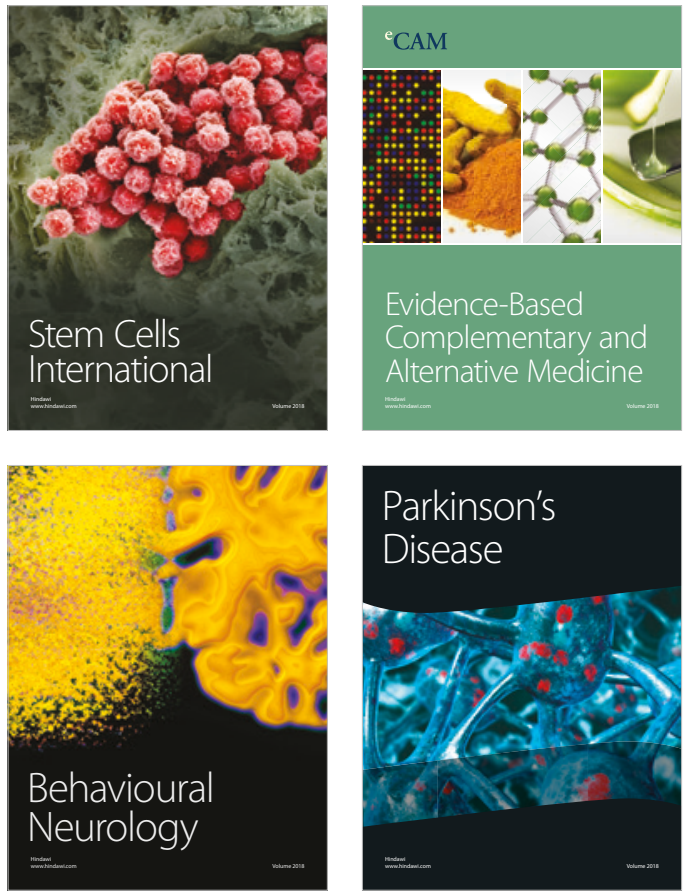

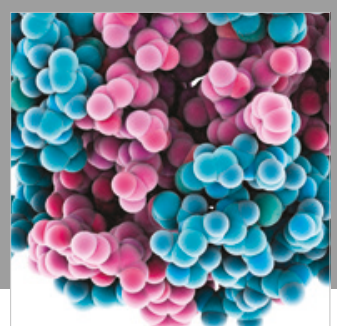

ournal of

Diabetes Research

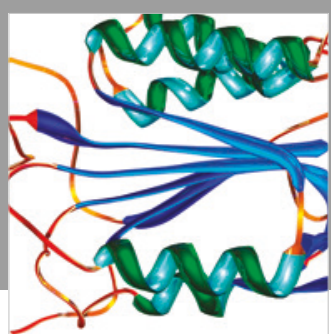

Disease Markers
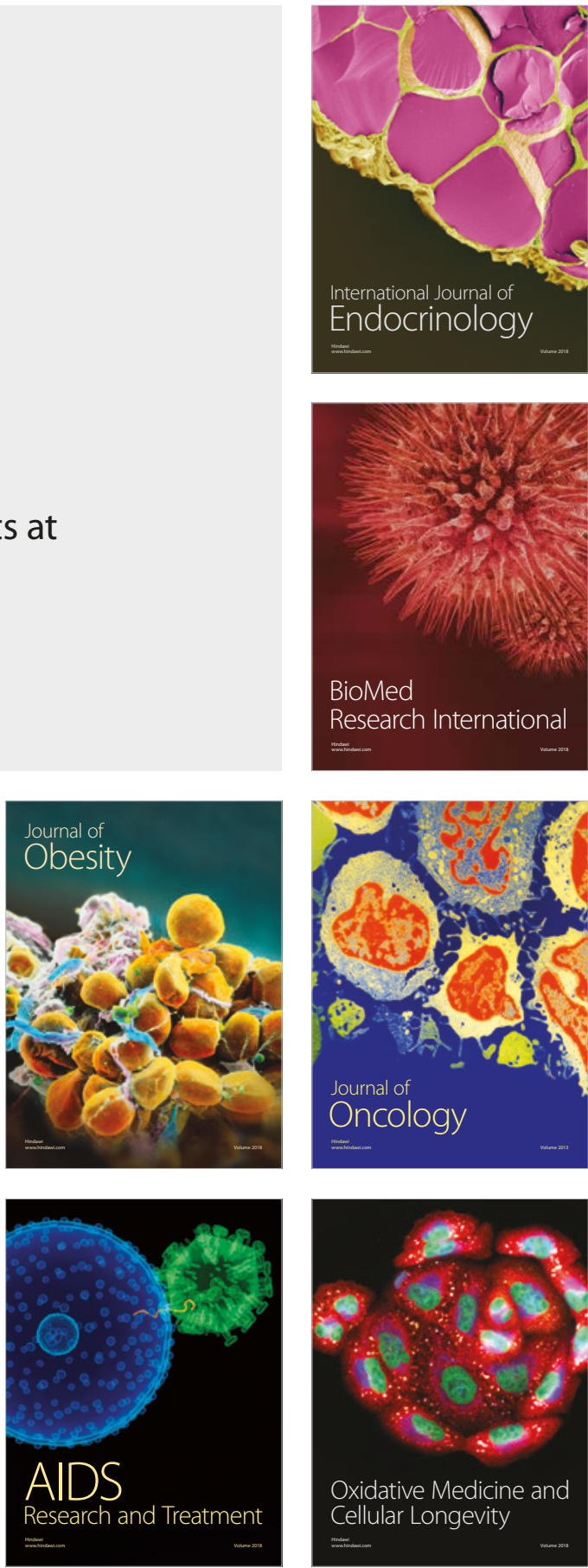